\title{
An Analysis and Modeling of the Class-E Inverter for ZVS/ZVDS at Any Duty Ratio with High Input Ripple Current
}

\author{
Ratil H. Ashique ${ }^{1, *}$, A. S. M. Shihavuddin ${ }^{1}\left(\right.$, Mohammad Monirujjaman Khan ${ }^{2}{ }^{\oplus}$, Aminul Islam ${ }^{3}{ }^{(}$, \\ Jubaer Ahmed ${ }^{4}$, M. Saad Bin Arif ${ }^{5}$, Md Hasan Maruf ${ }^{1}{ }^{\circledR}$, Ahmed Al Mansur ${ }^{1}{ }^{\circledR}$, Mohammad Asif ul Haq ${ }^{1}(\mathbb{D}$ \\ and Ashraf Siddiquee ${ }^{1}$
}

check for

updates

Citation: Ashique, R.H.;

Shihavuddin, A.S.M.; Khan, M.M.;

Islam, A.; Ahmed, J.; Arif, M.S.B.;

Maruf, M.H.; Al Mansur, A.; Haq,

M.A.u.; Siddiquee, A. An Analysis and Modeling of the Class-E Inverter for ZVS/ZVDS at Any Duty Ratio with High Input Ripple Current. Electronics 2021, 10, 1312. https:/ / doi.org/10.3390/electronics10111312

Academic Editor: Ahmed Abu-Siada

Received: 30 April 2021

Accepted: 25 May 2021

Published: 30 May 2021

Publisher's Note: MDPI stays neutral with regard to jurisdictional claims in published maps and institutional affiliations.

Copyright: (c) 2021 by the authors. Licensee MDPI, Basel, Switzerland. This article is an open access article distributed under the terms and conditions of the Creative Commons Attribution (CC BY) license (https:/ / creativecommons.org/licenses/by/ $4.0 /)$.
1 Department of Electrical and Electronic Engineering, Green University of Bangladesh, Dhaka 1207, Bangladesh; shihav@eee.green.edu.bd (A.S.M.S.); maruf@eee.green.edu.bd (M.H.M.); mansur@eee.green.edu.bd (A.A.M.); asiful@eee.green.edu.bd (M.A.u.H.); ashraf@eee.green.edu.bd (A.S.)

2 Department of Electrical and Computer Engineering, North South University, Dhaka 1229, Bangladesh; monirujjaman.khan@northsouth.edu

3 Department of Mechanical Engineering, Technical University of Denmark, 2800 Kgs. Lyngby, Denmark; mais@mek.dtu.dk

4 Department of Electrical and Electronic Engineering, Swinburne University of Technology Malaysia, Sarawak 93350, Malaysia; JAhmed@swinburne.edu.my

5 Department of Electrical and Electronic Engineering, Aligarh Muslim University, Uttar Pradesh 202002, India; saad.ee@amu.ac.in

* Correspondence: ratil@eee.green.edu.bd

\begin{abstract}
This paper presents an analysis and modeling of the class-E inverter for ZVS/ZVDS execution at any duty ratio. The methodology is to determine the input current to the inverter analytically under the assumption that it always remains positive. The latter is ensured by proper selection of the input inductance such that the inverter always operates either in (1) the border condition mode or in (2) the continuous conduction mode regardless of the input ripple. Using this input current and applying the boundary conditions, the required input capacitance for the ZVS/ZVDS execution is determined at a specified input/output voltage, output power and load. The analysis shows that the ZVS/ZVDS can be achieved while the input capacitance is selected appropriately. A comparison between the analytical and simulation results is also formulated involving the proposed and other existing models. The simulation results that are provided at different duty ratios demonstrate that they are in a better agreement with the proposed analytical model regardless of the input inductance and the state of input ripple current. The analytical modeling is facilitated by using MAPLE ${ }^{\circledR}$.
\end{abstract}

Keywords: Class E; Class EF2; Class E/F3; ZVS; Soft Switching

\section{Introduction}

The class-E inverter has found numerous applications in radio transmission, induction heating, industrial ultrasonic, renewable energy systems or commercial electronics industry [1-5]. In that regard, many application-specific designs are also proposed [3-7]. The widespread adoption of this inverter is mainly due to the compact topology with low component count and the capability of the circuit to deliver high power. On top of that, it can operate at high switching frequency with high efficiency if coupled with the zero-voltage switching (ZVS) or zero derivative voltage switching (ZVDS) techniques. The analysis and modeling of the ZVS/ZVDS class-E inverters are well reported in the literature [1-16]. Some of these modeling techniques are described here $[1,2,8,11,12]$. These techniques assume that the resonant current is sinusoidal, and, most importantly, the input current is a pure dc with very low ac component. The latter can be achieved if the input inductance is kept sufficiently large. Consequently, these models can define the behavior of the input current with the change in duty ratio. However, at lower inductances 
and higher ripple current, the assumption is no longer valid. The input current to the inverter is dependent on the input inductance, the input capacitance along with the duty ratio of the circuit. Consequently, the existing modeling techniques [1-9,12-16]. fail to define the input current accurately. This inaccuracy further leads to miscalculation of the input/output power and the efficiency of the circuit. Henceforth, this work proposes an input current-based modeling of the class-E inverter. This proposed modeling technique has the following key features:

(1) It provides an analysis and modeling of the class-E ZVS/ZVDS inverter for any duty ratio.

(2) More accurate modeling of the input current, regardless of the input inductance and input ripple current. This feature helps to determine the input power and efficiency more accurately.

(3) The model can ensure the ZVS/ZVDS operation at any given load.

In the following sections, this model is discussed, analyzed and compared with the simulated results. The analytical modeling presented is performed using MAPLE ${ }^{\circledR}$.

\section{The Circuit Operation of Class-E Inverter}

The topology of the class-E inverter is given in Figure 1. The inductance $\mathrm{Lr}$ and the capacitance $C_{r}$ is chosen to resonate at $f_{r}$, which is also the switching frequency of the inverter. The $L_{f}$ can be chosen to provide a constant dc current. However, the input ripple current percentage will increase with the decreasing size of the inductance $L_{f}$. The input capacitance $C_{i n}$ is inclusive of any parasitic drain to source capacitance of the switch and any external capacitance added. The switch $\mathrm{S} 1$ is operated with a duty ratio $D$. The switching pattern is given as follows.

$$
\text { Switch }=\left\{\begin{array}{l}
\text { Turned ON, } \quad 0 \leq \theta<2 \pi D \\
\text { Turned OFF, } \quad 2 \pi D \leq<\theta<2 \pi
\end{array}\right.
$$

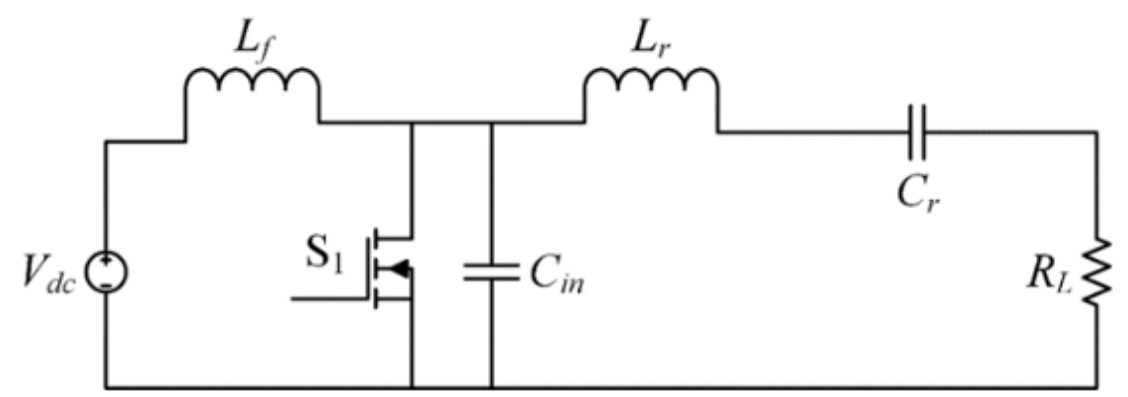

Figure 1. The class-E inverter.

\subsection{Modes of Operation}

The circuit is operated in two modes. In mode 1, the switch is turned ON and the voltage across the capacitor $C_{i n}$ falls to zero. The input current flows through the switch $S_{1}$ and the $L_{f}$ is charged. In the resonant tank, resonant current flows to the switch direction exchanging stored energy from $C_{r}$ to $L_{r}$ and completing half of the resonance cycle. This is shown in Figure 2a. In mode 2 (Figure $2 b$ ), the switch $S_{1}$ is turned off and the input current $I_{\text {in }}$ is diverted to the input capacitance $C_{i n}$. At this moment, the input capacitor is charged to the peak switch voltage. Subsequently, it is discharged to zero at the end of this mode aiding in ZVS/ZVDS turn on of $S_{1}$. If we assume the switch voltage is vs $(\theta)$, the following conditions must be satisfied in order to achieve ZVS or ZVDS:

$$
v_{s}(2 \pi)=0
$$

and

$$
\frac{d}{d \theta} v_{S}(2 \pi)=0
$$




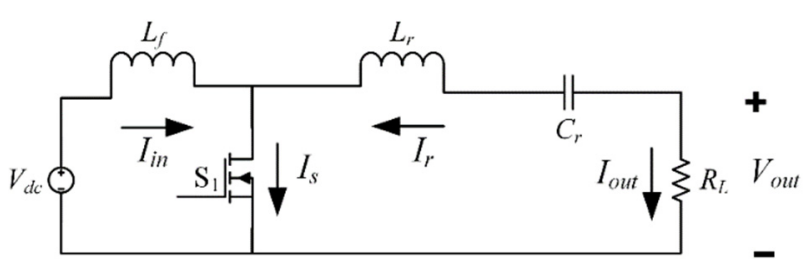

(a)

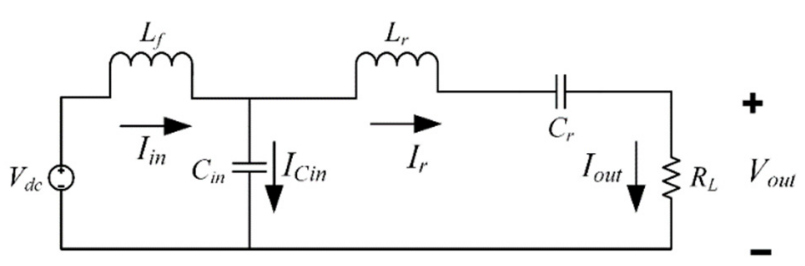

(b)

Figure 2. The class-E converter in (a) Mode 1 (b) Mode 2.

The class-E inverter operating modes are shown in Figure 2. The current through the switch diverts to charge the input capacitor $C_{i n}$ when the switch is closed at $\theta=2 \pi D$. As soon as $C_{i n}$ is charged completely, the current alters direction and $C_{\text {in }}$ discharges. Due to the inductive effect of the resonant tank in Mode 2, the output current $\left(I_{\text {out }}\right)$ lags the output voltage $\left(V_{\text {out }}\right)$.

\subsection{Assumptions}

The circuit analysis is performed by applying the following assumptions.

a. All the components are ideal and do not possess any parasitic resistance or capacitances.

b. The switch is ideal. It is an open circuit $\left(v_{\mathcal{S}}=\infty\right)$ while OFF and shorted $\left(v_{\mathcal{S}}=0\right)$ while ON.

c. The input current $\left(I_{\text {in }}\right)$ is always positive.

\section{The Circuit Modeling}

3.1. Modeling Approach

Given,

$$
N=\frac{L_{f}}{L_{f \_b o u n d a r y}}
$$

where, $L_{f \_ \text {boundary }}=$ boundary value of the input inductor $\left(L_{f}\right)$ while the inverter operates at the border condition mode (BCM) and $N=$ inductance ratio.

Now, the modeling approach is stated as follows

Step 1: To determine the switch voltage $\left(v_{S}(\theta)\right)$

Step 2: To apply the boundary conditions for ZVS/ZVDS and find input current $\left(I_{\text {in }}(\theta)\right)$

Step 3: To find $L_{f_{-} \text {boundary }}$ and the input ripple current $\left(\Delta i_{i n}\right)$

Step 4:

Case $1(N \approx 1)$

(1) To determine the average input current $\left(I_{\text {in_avg_case } 1}\right)$

(2) Using $I_{\text {in_avg_case } 1}$ to find the input capacitance $\left(C_{\text {in_case } 1}\right)$

Case $2(1.5<N<3)$

(1) To determine the average input current ( $\left.I_{\text {in_avg_case2 }}\right)$

(2) Using $I_{\text {in_avg_case } 2}$ to find the input capacitance $\left(C_{\text {in_case } 2}\right)$

Case $3(N \geq 3)$

(1) To determine the average input current ( $\left.I_{\text {in_avg_case3 }}\right)$

(2) Using $I_{\text {in_avg_case3 }}$ to find the input capacitance $\left(C_{\text {in_case3 }}\right)$

Step 5: To find the peak switch voltage $\left(v_{s_{-} p k}\right)$ and the peak switch current $\left(i_{s_{-} p k}\right)$

\subsection{The Derivation}

\subsubsection{Step 1}

If the current through the input capacitor $\left(C_{i n}\right)$ is $I_{C i n}$, the switch voltage can be expressed as 


$$
v_{S}(\theta)=\frac{1}{\omega C_{i n}} \int_{2 \pi D}^{\theta} I_{C i n} d \theta
$$

From Figure $2 \mathrm{a}$, the input current $I_{\text {in }}$ can be written as

$$
I_{\text {in }}(\theta)=I_{\text {Cin }}(\theta)+I_{r}(\theta)
$$

where

$I_{r}(\theta)$ is the resonant current;

$I_{C i n}$ is the capacitor current;

$I_{\text {in }}(\theta)$ is the input current.

From (1),

$$
v_{S}(\theta)=\frac{1}{\omega C_{i n}} \int_{2 \pi D}^{\theta}\left(I_{\text {in_avg }}-I_{m} \sin (\theta+\varphi)\right) d \theta
$$

Simplifying,

$$
v_{\mathcal{S}}(\theta)=\frac{-2 I_{\text {in_avg }} \pi D-I_{m} \cos (2 \pi D+\varphi)+I_{\text {in_avg }} \theta+I_{m} \cos (\theta+\varphi)}{\omega C_{\text {in }}}
$$

\subsubsection{Step 2}

Applying $v_{S}(2 \pi)=0$ for ZVS to (4),

$$
I_{m}=\frac{2 \pi I_{i n \_a v g}(1-D)}{\cos (2 \pi D+\varphi)-\cos \varphi}
$$

or

$$
I_{\text {in_avg }}=\frac{I_{m}(\cos (2 \pi D+\varphi)-\cos \varphi)}{2 \pi(1-D)}
$$

Again, applying $v_{S}(2 \pi)=0$ and using (5) and (6),

$$
\varphi=\pi+\arctan \left(\frac{\cos (2 \pi D)-1}{2 \pi(1-D)+\sin (2 \pi D)}\right)
$$

Now, replacing (6) into (4) and simplifying (A1) (see Appendix A) is obtained. The output power to the load is defined by

$$
P_{\text {out }, r m s}=\left(\frac{I_{m}}{\sqrt{2}}\right)^{2} R_{L}
$$

or

$$
I_{m}=\sqrt{\frac{2 P_{\text {out }, r m s}}{R_{L}}}
$$

where $R_{L}$ is the given load resistance. Now, replacing $I_{m}$ from (9) into (7) and simplifying (A2) (see Appendix A) is obtained. The inductor $v_{L f}$ voltage can be expressed as

$$
v_{L_{f}}(\theta)=\omega L_{f} \frac{d}{d \theta} I_{i n}(\theta)
$$

Now,

$$
v_{L_{f}}=\left\{\begin{array}{l}
V_{\text {in }} \text { if } 0 \leq \theta<2 \pi D \\
V_{\text {in }}-v_{s}(\theta) \text { if } 2 \pi \mathrm{D} \leq \theta \leq \theta
\end{array}\right.
$$

Now, considering the initial conditions, the current through $L_{f}$ can be written as expressed in (A3) (see Appendix A). Now, $f_{n}(\theta)$ can be written as 


$$
f_{n}(\theta)=\frac{1}{\omega L_{f}} \int_{(n-1) \pi}^{\theta} V_{i n} d \theta
$$

where (12) is extended in (A4) (see Appendix A). If $n$ is odd and $m$ is even, by generalizing, (A4) and (A5) (see Appendix A) can be obtained for $n$ and $m$, respectively.

\subsubsection{Step 3}

The boundary value of the input inductor can be determined by the following:

$$
\Delta I_{\text {in }}=I_{\text {in }}(2 \pi D)-I_{\text {in }}(0)=\frac{2 \pi D V_{\text {in }}}{\omega L_{f_{-} \text {boundary }}}
$$

which gives

$$
L_{f \_b o u n d a r y}=\frac{2 \pi D V_{\text {in }}}{\omega \Delta I_{\text {in }}}
$$

Now, the ripple current can be measured as

$$
\Delta I_{\text {in }}=I_{\text {in }}(2 \pi D)-I_{\text {in }}(2 \pi)
$$

Substituting the values of $I_{\text {in }}$ from (A4) and (A5) and simplifying, the following is obtained:

$$
\Delta I_{i n}=\frac{\sqrt{\frac{2 P_{\text {out }, \text { rms }}}{R_{L}}}\left(D^{2}-2 \pi D+\pi\right)+2 \pi \omega V_{\text {in }} C_{i n}(D-1)(2 D-1)}{(D-1) \omega^{2} C_{i n} L_{f}}
$$

\subsubsection{Step 4}

(a) Case 1: The input average current and the input capacitance for $N \approx 1$

Now, if $N \approx 1$, the current is always positive and the inverter operates in close proximity of the $\mathrm{BCM}$ with high ripple current. The theoretical input current waveform is shown in Figure 3. In this case, the average current can be defined as

$$
I_{\text {in_avg_case } 1}=\frac{1}{2 \pi}\left(\int_{0}^{2 \pi D} I_{i n \_1}(\theta) d \theta+\int_{2 \pi D}^{2 \pi} I_{i n \_2}(\theta) d \theta\right)
$$

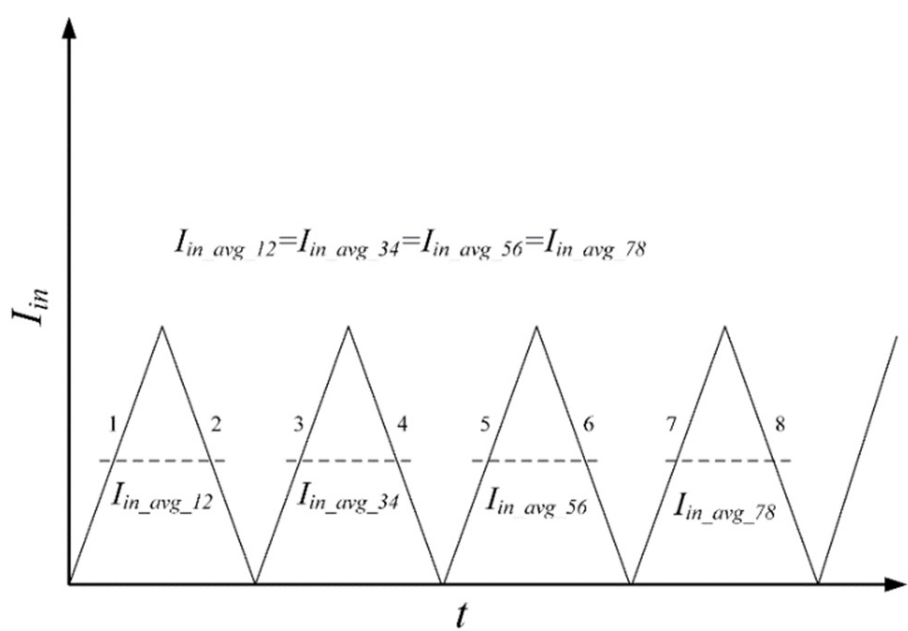

Figure 3. The theoretical input current when $N \approx 1$ and $D=0.50$. Assume usual units for all parameters. 
Now, simplifying (17) and using (A6)-(A8) can be obtained, which is shown in the Appendix A; where

$$
\begin{gathered}
A=\sqrt{2} \pi(D-1) \cos \varphi(1-\sqrt{2})+\sin \varphi \\
B=\cos \varphi+\pi(D-1) \sin \varphi \\
C=-\sin \varphi-\pi(D-1) \cos \varphi
\end{gathered}
$$

Again, from (3), (A9) (see Appendix A) is obtained. Alternatively, the average current (In_avg_case1_alt) ) can be found (while $n=5$ and $m=6$ ) as shown in (A10) (see Appendix A). Accordingly, solving and simplifying (A10), (A11) (see Appendix A) is obtained, where

$$
\begin{aligned}
& A^{\prime}=\pi(D+3) \cos \varphi-\sin \varphi \\
& B^{\prime}=\cos \varphi+\pi(D+3) \sin \varphi
\end{aligned}
$$

Now, the output power of the converter is

$$
P_{\text {out }, r m s}=\left(\frac{I_{m}}{\sqrt{2}}\right)^{2} R_{L}=\frac{\left(\frac{V_{\text {out } \text { peak }}}{\sqrt{2}}\right)^{2}}{R_{L}}
$$

Now, $I_{m}$ from (9) for case 1 is

$$
I_{m}=\frac{2 \pi I_{\text {in_avg_case } 1}(1-D)}{\cos (2 \pi D+\varphi)-\cos \varphi}
$$

Replacing from (19) in (18), $P_{\text {out }, \text { rma }}$ is obtained as demonstrated in (A12) (see Appendix A). Then, (A12) is solved for $C_{i n}$, where $N_{1}$ and $D_{1}$ are demonstrated in (A13) and (A14) (see Appendix A).

$$
C_{\text {in_case } 1}=\frac{N_{1}}{D_{1}}
$$

The negative quotient of $C_{i n \_ \text {case } 1}$ is neglected.

(b) Case 2: The input average current and the input capacitance for $1.5<N<3$ :

In this case, the input inductor is slightly greater than the $L_{f-b o u n d a r y}$ (approximately 1.5 to 2.5 times of $L_{f_{-} \text {boundary }}$ ). The $L_{f_{-} \text {boundary, }}$, which is calculated from (14), is $50 \mu \mathrm{H}$ and $55 \mu \mathrm{H}$ at $D=0.55$ and 0.50 , respectively. The theoretical input current waveform is shown in Figure 4. The current is always positive and the inverter operates at the continuous conduction mode $(\mathrm{CCM})$ with high current ripple. The average current $I_{\text {in_avg_case_alt }}$ as derived in (29) is appropriate. However, due to the transient nature of the input current, $I_{\text {in_avg_sum } 34}$ is determined to define the input current more accurately.

For a better understanding, $I_{\text {in_avg_78 }}$ is derived in (A15), where

$$
A^{\prime}=\pi(D+3) \cos \varphi-\sin \varphi B^{\prime}=\cos \varphi+\pi(D+3) \sin \varphi
$$

The current is shown in Figure 5. Now, using (21) and (A16) (see Appendix A) is solved for $C_{i n}$ as demonstrated in (A17) (see Appendix A). The negative quotient of $C_{\text {in_case2 }}$ is neglected. 


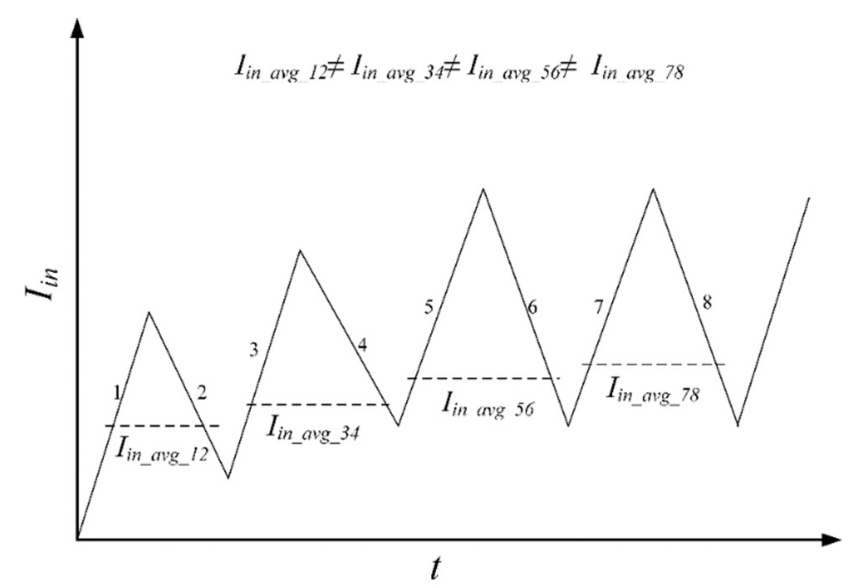

Figure 4. The theoretical input current when $1<N<3$ and $D=0.50$. Assume usual units for all parameters.

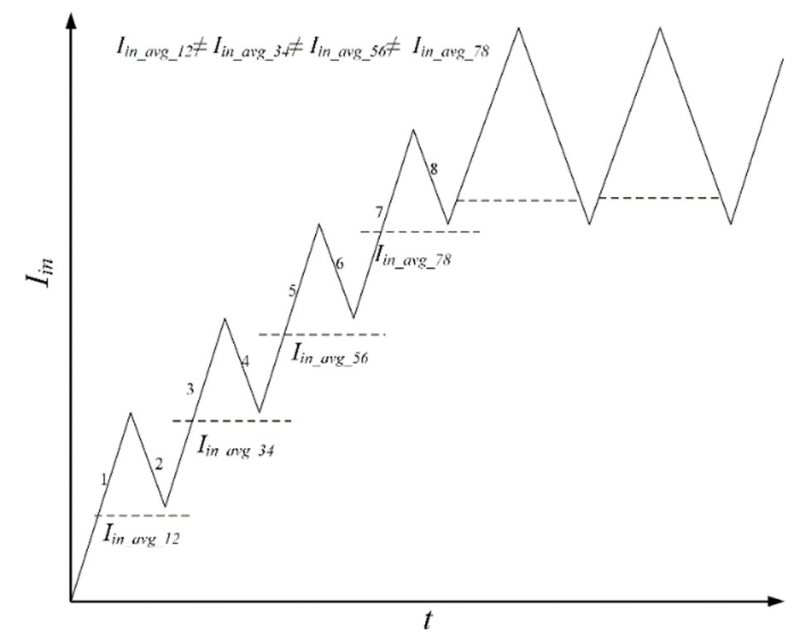

Figure 5. The theoretical input current when $N>3$ and $D=0.50$. Assume usual units for all parameters.

(c) Case 3-The input average current and the input capacitance for $N \geq 3$ :

In this case, the input inductor is greater than the $L_{f_{-} \text {boundary }}$ (approximately 3 to 5

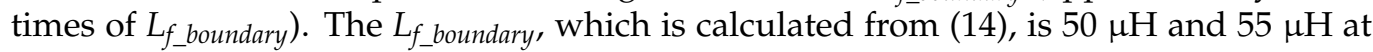
$D=0.55$ and 0.50 , respectively. The theoretical input current waveform is shown in Figure 5 . The current is always positive and the inverter operates at the continuous conduction mode (CCM) with low current ripple. Moreover, in this case, $I_{\text {in_avg_case } 2}$ is sufficient. However, $I_{\text {in_avg_15-16 }}$ is determined to define the input current more accurately. The $C_{\text {in_case } 3}$ is shown in (A20).

Hence,

$$
\begin{gathered}
I_{\text {in_avg_case3 }}=I_{\text {in_avg_case2 }}=I_{\text {in_avg_78 }} \\
I_{\text {in_avg_case3_alt }}=I_{\text {in_avg_15-16 }}
\end{gathered}
$$

Replacing values in (22) and simplifying, (A18) (see Appendix A) is obtained.

\subsubsection{Step 5}

The switch voltage can be determined from (3), (6) and (9). Now, if $n=6$, solving for $d v_{s} / d \theta=0$,

$$
\theta_{p k}=-\varphi-\arcsin \left(\frac{1}{2 \pi(D-1)}\right)
$$


Replacing $\theta_{p k}$ from (23) into (A19) (see Appendix A) gives the peak switch voltage,

$v_{s_{-} p k}=\frac{1}{2 \pi \omega C_{i n}(D-1)} \sqrt{\frac{2 P_{o u t, r m s}}{R_{L}}}\left(\left(\sqrt{4 \pi^{2}(D-1)^{2}-1}\right)+\arcsin \left(\frac{1}{2 \pi(D-1)}\right)+\varphi\right)$

The switch current,

$$
I_{S}(\theta)=I_{\text {in }}-I_{m} \sin (\theta+\varphi)
$$

Replacing $I_{\text {in }}$ from (5),

$$
I_{S}(\theta)=\frac{I_{m}(\cos (2 \pi D+\varphi)-\cos \varphi)}{2 \pi(1-D)}-I_{m} \sin (\theta+\varphi)
$$

The current peaks at

$$
\theta=2 \pi D
$$

Hence, replacing from (23) and (24) in (26),

$$
i_{s_{-} p k}=\frac{\sqrt{\frac{2 P_{\text {out }, \text { rms }}}{R_{L}}}\left(\pi(D-1) \sin (2 \pi D+\varphi)-\frac{\cos \varphi}{2}+\frac{\cos (2 \pi D+\varphi)}{2}\right)}{\pi(D-1)}
$$

\section{Analysis of The Model Parameters}

\subsection{The Phase Difference $(\varphi)$ :}

The phase difference between the output voltage and current is given in (8). Now, if $D=0, \varphi=\pi$. Again, if $D=1, \varphi$ is undefined $(0 / 0)$.

In Figure 6, $\varphi$ is plotted against $D$. At $D=0, \varphi$ is maximum at $\pi$. As $D$ increases, the phase difference decreases.

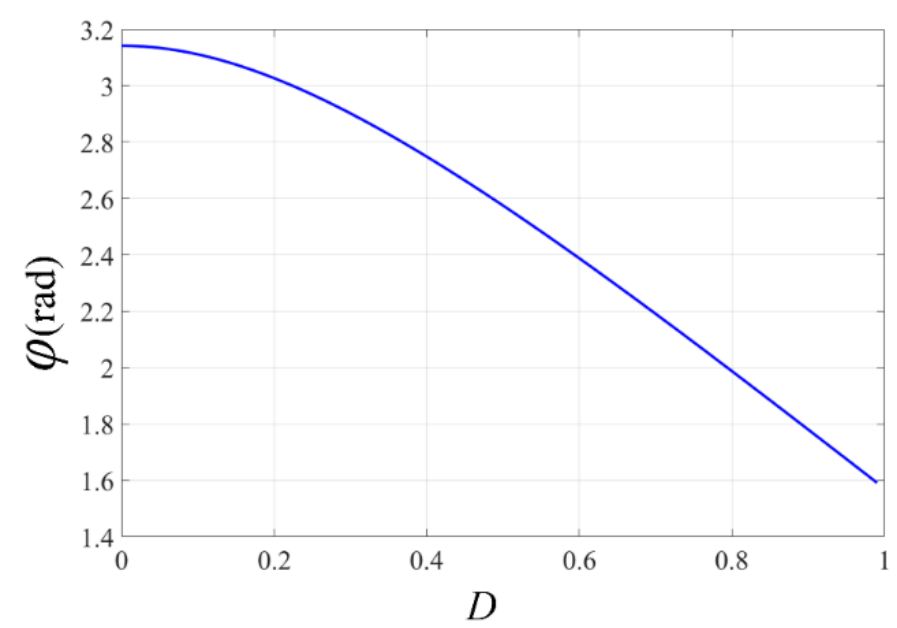

Figure 6. The phase difference against $D$ at $V_{\text {in }}=15 \mathrm{~V}, V_{\text {out_peak }}=20 \mathrm{~V}, P_{\text {out_rms }}=10 \mathrm{~W}$ and $f_{s}=150 \mathrm{kHz}$.

\subsection{The Input Current Ripple}

The input current ripple decreases with increasing size of $L_{f}$.

In Figure 7, the input current ripple percentage is demonstrated against $L_{f}$. As $L_{f}$ decreases, the ripple percentage increases according to (13). However, the input current $\left(I_{\text {in }}\right)$ remains positive as long as $L_{f}>L_{f_{-} \text {boundary }}$. 


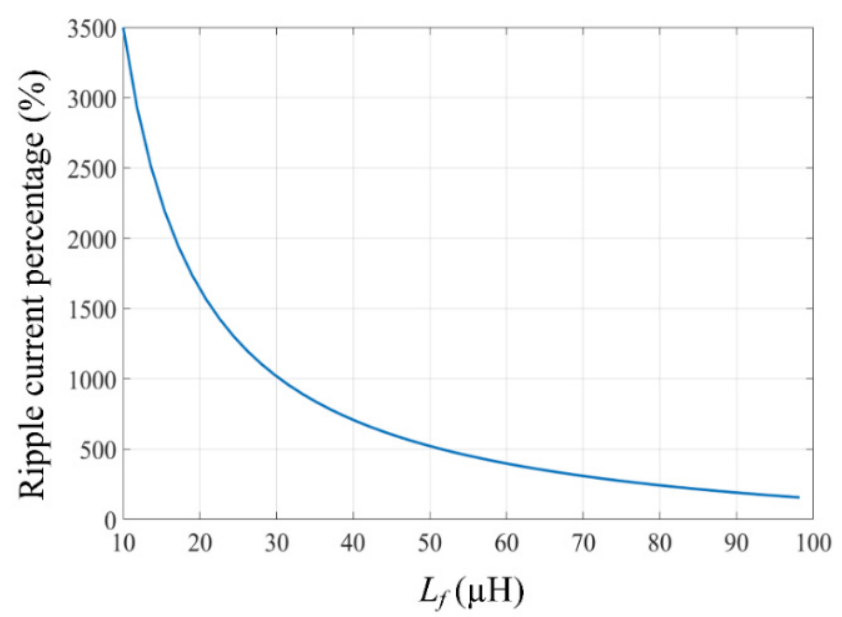

Figure 7. $L_{f}$ vs. $M$ (input current ripple percentage) at $D=0.55, V_{\text {in }}=15 \mathrm{~V}, V_{\text {out }}=20 \mathrm{~V}, P_{\text {out }}=10 \mathrm{~W}$, $C_{\text {in }}=13 \mathrm{nF}$ and $f_{s}=150 \mathrm{kHz}$.

\subsection{The Input Capacitance $\left(C_{i n}\right)$}

\subsubsection{Case 1}

In Figure $8 \mathrm{a}, \mathrm{b}, C_{\text {in case } 1}$ is plotted against $D$ and $L_{f}$, respectively, while $V_{\text {in }}=15 \mathrm{~V}$, $V_{\text {out_peak }}=20 \mathrm{~V}, P_{\text {out_rms }}=10 \mathrm{~W}$ and $f_{s}=150 \mathrm{kHz}$. As obvious from Figure $9 \mathrm{a}, C_{\text {in_case } 1}$ is always positive for $D_{c r} \geq 0.52, D_{c r} \geq 0.48$ and $D_{c r} \geq 0.41$, while $L_{f}=50,55$ and $70 \mu \mathrm{H}$, respectively. In Figure $8 b, C_{\text {in_case } 1}$ is positive for $L_{f_{-} c r}>52.8$ and $L_{f_{-} c r}>46.4$ for $D=0.55$ and 0.50 , respectively. To achieve ZVS/ZVDS, these critical duty ratio and input inductances have to be maintained with $C_{\text {in_casel }}$ being chosen appropriately under the specified conditions.

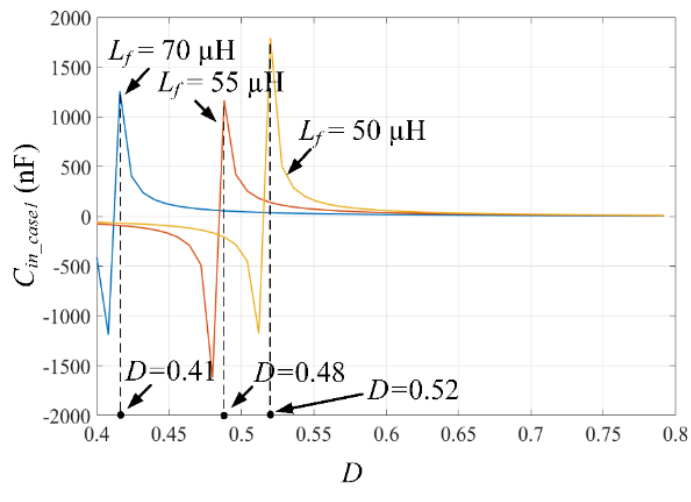

(a)

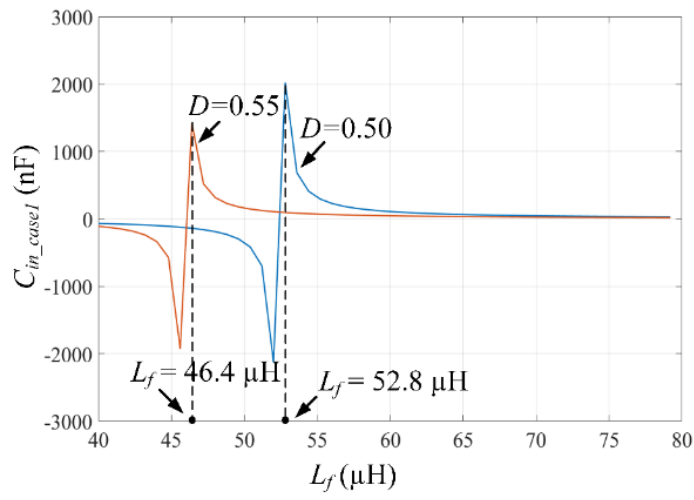

(b)

Figure 8. (a) $C_{\text {in_case } 1}$ vs. $D$ at $L_{f}=50,55$ and $70 \mu \mathrm{H}(\mathbf{b}) C_{\text {in_case } 1}$ vs. $L_{f}$ at $D=0.50$ and 0.55 , while $V_{\text {in }}=15 \mathrm{~V}, V_{\text {out_peak }}=20 \mathrm{~V}$, $P_{\text {out }}=10 \mathrm{~W}$ and $f_{s}=150 \mathrm{kHz}$.

\subsubsection{Case 2}

In Figure $9 \mathrm{a}, \mathrm{b}, C_{\text {in_case } 2}$ is plotted against $D$ and $L_{f}$, respectively, while $V_{\text {in }}=15 \mathrm{~V}$, $V_{\text {out_peak }}=20 \mathrm{~V}, P_{\text {out_rms }}=10 \mathrm{~W}$ and $f_{s}=150 \mathrm{kHz}$. As obvious from Figure $10 \mathrm{a}, C_{\text {in_case2 }}$ is always positive for $D_{c r} \geq 0.52, D_{c r} \geq 0.54$ and $D_{c r} \geq 0.60$, while $L_{f}=100,90$ and $80 \mu \mathrm{H}$, respectively. In Figure $9 \mathrm{~b}, C_{\text {in_case } 2}$ is positive for $L_{f_{-} c}>92.5$ and $L_{f_{-} c r}>105.2$ for $D=0.55$ and 0.50 , respectively. To achieve ZVS/ZVDS, these critical duty ratio and input inductances have to be maintained with $C_{\text {in_case1 }}$ being chosen appropriately under the specified conditions. 


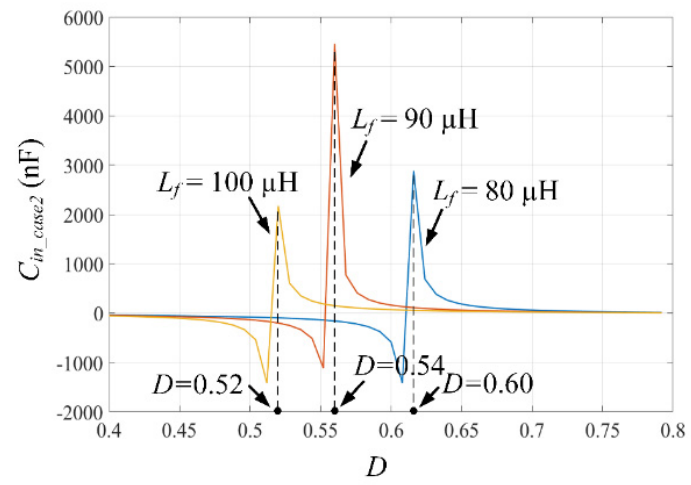

(a)

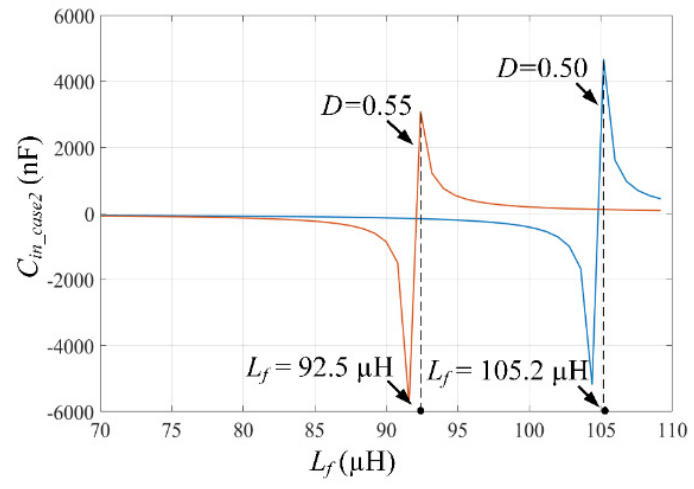

(b)

Figure 9. (a) $C_{\text {in_case2 } 2}$ vs. $D$ at $L_{f}=80,90$ and $100 \mu \mathrm{H}$ (b) $C_{\text {in_case } 1}$ vs. $L_{f}$ at $D=0.50$ and 0.55 , while $V_{\text {in }}=15 \mathrm{~V}, V_{\text {out_peak }}=20 \mathrm{~V}$, $P_{\text {out }}=10 \mathrm{~W}$ and $f_{s}=150 \mathrm{kHz}$.

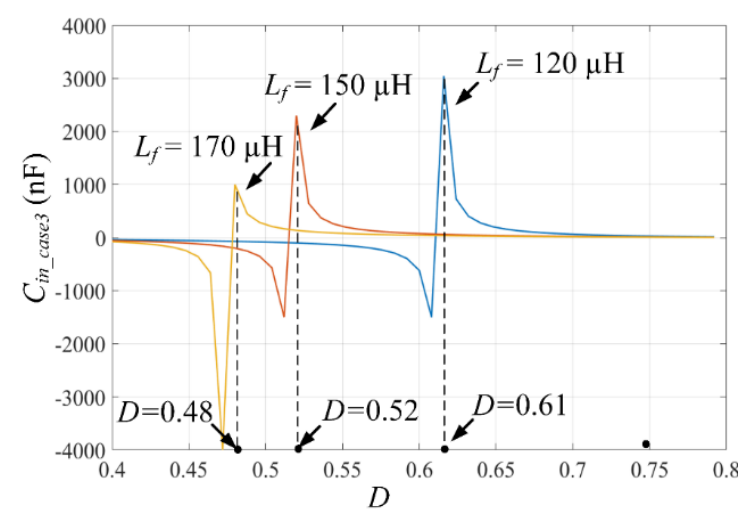

(a)

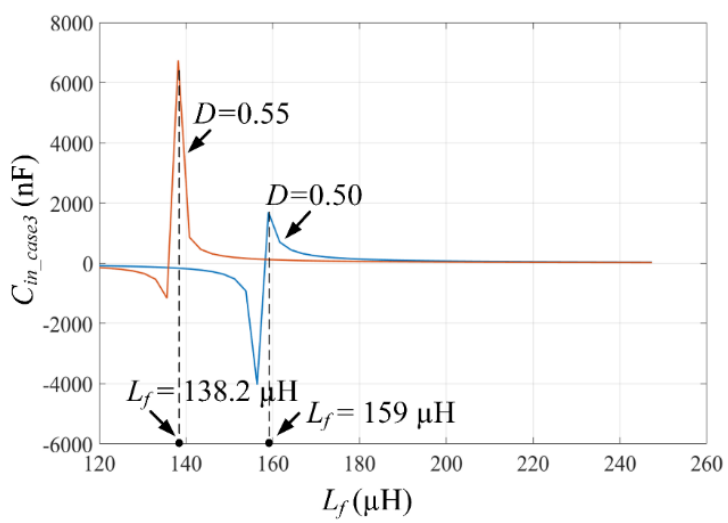

(b)

Figure 10. (a) $C_{\text {in_case3 }}$ vs. $D$ at $L_{f}=120,150$ and $170 \mu \mathrm{H}$ (b) $C_{\text {in_case } 3}$ vs. $L_{f}$ at $D=0.50$ and 0.55 , while $V_{\text {in }}=15 \mathrm{~V}, V_{\text {out_peak }}=$ $20 \mathrm{~V}, P_{\text {out }}=10 \mathrm{~W}$ and $f_{s}=150 \mathrm{kHz}$.

\subsubsection{Case 3}

In Figure 10a,b, $C_{\text {in_case3 }}$ is plotted against $D$ and $L_{f}$, respectively, while $V_{\text {in }}=15 \mathrm{~V}$, $V_{\text {out_peak }}=20 \mathrm{~V}, P_{\text {out_rms }}=10 \mathrm{~W}$ and $f_{s}=150 \mathrm{kHz}$. As obvious from Figure $10 \mathrm{a}, C_{\text {in_case } 3}$ is always positive for $D_{c r} \geq 0.48, D_{c r} \geq 0.52$ and $D_{c r} \geq 0.61$, while $L_{f}=170,150$ and $120 \mu \mathrm{H}$, respectively. In Figure $10 \mathrm{~b}, C_{\text {in_case } 2}$ is positive for $L_{f_{-} c r}>138.2$ and $L_{f_{-} c r}>159$ at $D=0.55$ and 0.50 , respectively. To achieve ZVS/ZVDS, these critical duty ratio and input inductances have to be maintained with $C_{i n \_}$cases 3 being chosen appropriately under the specified conditions.

\subsection{Peak Switch Voltage $\left(V_{s-p k}\right)$}

The peak switch voltage $\left(v_{s_{-} p k}\right)$ from (24) is demonstrated in Figure 11. The rating of the switch should be 2-3 times the peak voltage for safe operation under the specified operating conditions. Moreover, from Figure 12b, it is obvious that the peak switch voltage can be lowered by lowering the output power at a given $D$ and $R_{L}$. Similarly, it can be lowered by lowering the $R_{L}$ at a given $D$ and $P_{\text {out_rms }}$ as obvious from Figure 12c. However, for both cases, the output voltage is also affected with $v_{s_{-} p k}$. 


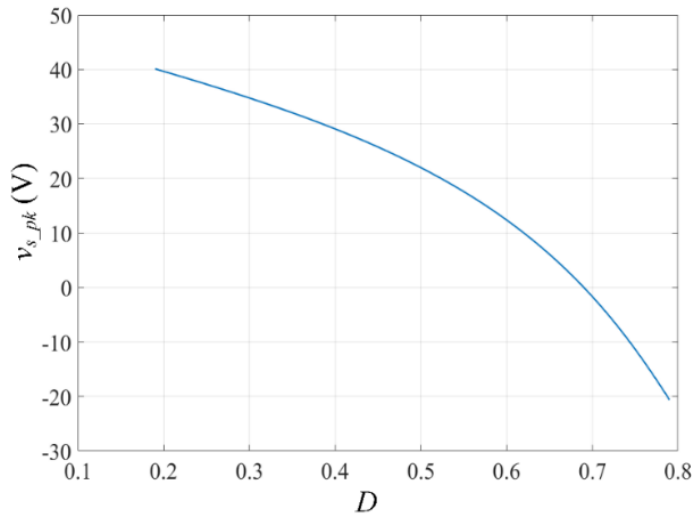

(a)

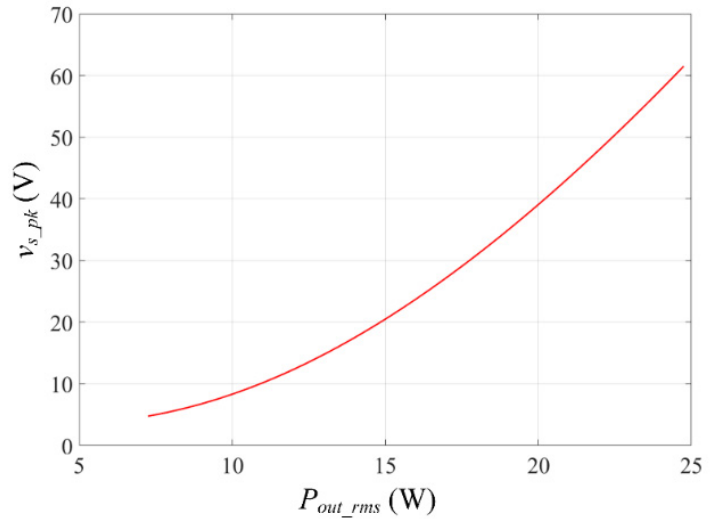

(b)

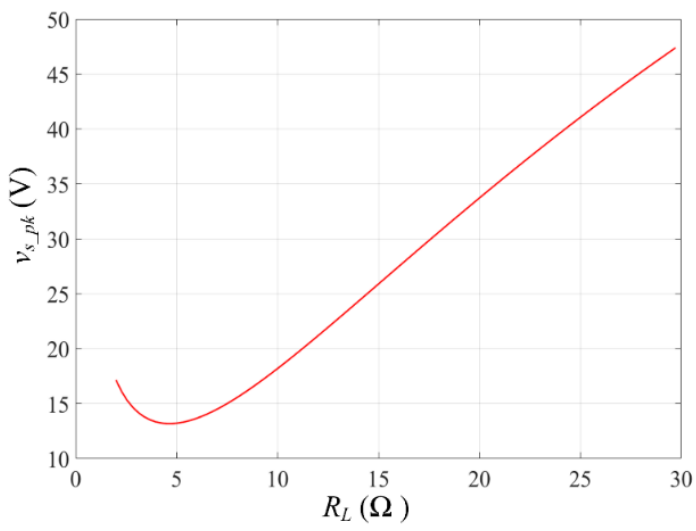

(c)

Figure 11. The peak switch voltage $\left(v_{s_{s} p k}\right)$ against (a) $D$ while $V_{\text {in }}=15 \mathrm{~V}, V_{\text {out_peak }}=20 \mathrm{~V}, R_{L}=25 \Omega, P_{\text {out_rms }}=10 \mathrm{~W}$ and $f_{s}=150 \mathrm{kHz}(\mathbf{b}) P_{\text {out_rms }}$ while $D=0.5, V_{\text {in }}=15 \mathrm{~V}, V_{\text {out_peak }}=20 \mathrm{~V}, R_{L}=25 \Omega$ and $f_{s}=150 \mathrm{kHz}(\mathbf{c}) R_{L}$ while $D=0.5, V_{\text {in }}=15 \mathrm{~V}$, $V_{\text {out_peak }}=20 \mathrm{~V}, P_{\text {out_rms }}=10 \mathrm{~W}$ and $f_{s}=150 \mathrm{kHz}$.

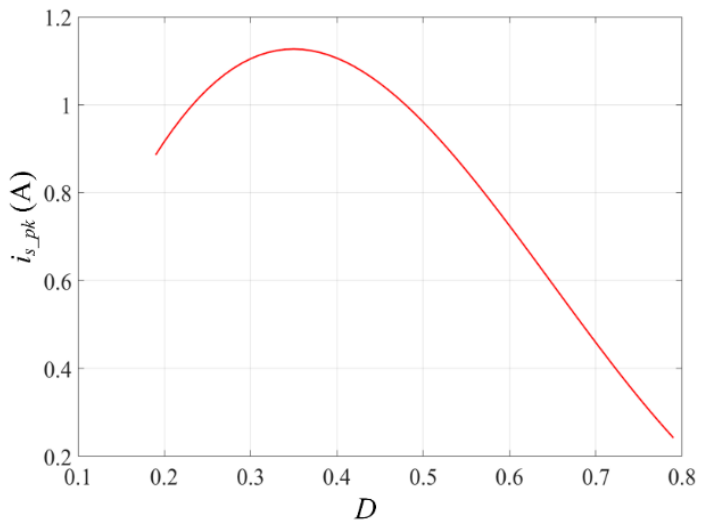

Figure 12. The peak switch current $\left(i_{s \_p k}\right)$ against $D$.

\subsection{Peak Switch Current $\left(i_{s-p k}\right)$}

The peak switch current $\left(i_{s \_p k}\right)$ from $(28)$ is demonstrated in Figure 12 . The peak current has a maximum in the mid region of $D(0.3$ to 0.5$)$ and gradually decreases on both sides. Hence, given the optimum $D=0.5$, the rating of the switch should be $2-3$ times the peak current for safe operation. 


\section{Simulation and Experimental Verification}

The class-E inverter is simulated in MATLAB Simulink environment to demonstrate the waveforms. Table 1 demonstrates the common parametric values.

Table 1. Specifications for Class-E Inverter.

\begin{tabular}{cc}
\hline Parameter & Value \\
\hline$V_{\text {in }}$ & $15 \mathrm{~V}$ \\
$V_{\text {out_peak }}$ & $20 \mathrm{~V}$ \\
$P_{\text {out_rms }}$ & $10 \mathrm{~W}$ \\
$f_{s}, f_{r}$ & $0.50,0.55$ \\
$R_{L}$ & $150 \mathrm{kHz}$ \\
$C_{\text {out }}$ & $25 \Omega$ \\
$C_{\text {in }}$ & $10 \mathrm{nF}$ \\
$L_{f}$ & $13 \mathrm{nF}$ and $72 \mathrm{nF}$ \\
$L_{r}$ & $50 \mu \mathrm{H}$ and $55 \mu \mathrm{H}$ \\
$C_{r}$ & $1.3 \mathrm{mH}$ \\
\hline
\end{tabular}

Case-1: Boundary Conduction Mode $(\mathrm{N} \approx 1)$.

The $L_{r}$ and $C_{r}$ is selected to maintain a high loaded $Q_{L}$ factor $\left(Q_{L} \geq 10\right)$, which is given as

$$
Q_{L}=\frac{\omega L_{r}}{R_{L}}
$$

Hence, the resonance frequency of the circuit is

$$
f_{r}=\frac{1}{2 \pi \sqrt{L_{r} C_{r}}}
$$

Once, $L_{r}$ is selected for the desired $Q_{L}$ from (46), $C_{r}$ can be determined.

In this case, the input inductor is equal or close to the $L_{f-b o u n d a r y}$. The $L_{f_{-} \text {boundary }}$, which is calculated from (14), is $50 \mu \mathrm{H}$ and $55 \mu \mathrm{H}$ at $D=0.55$ and 0.50 , respectively. The output voltage and power of the inverter should demonstrate the specified value with minimal error. In addition, the average input current from the simulation must concur with the analytical value from (A8). Accordingly, as $C_{i n}$ is implemented calculated from (A17), the ZVS/ZVDS should be executed.

The circuit is simulated at the designated parametric values stated in Table 1. The output voltage and power waveforms are shown in Figure 13 for $D=0.50$. As opposed to the ideal lossless analytical model, the switch in the simulation induces a conduction loss across the ON resistance $\left(R_{d s-O N}=0.015 \Omega\right)$.

In Figure 14, the analytical values of $V_{\text {in }}, V_{\text {out }}, P_{\text {in }}, P_{\text {out }}, \eta, I_{\text {in_avg }}, I_{m}$ from the proposed model and [1,2] are stated along with the simulated results for $D=0.55$ and 0.50 . The percentage differences between the analytical and simulation results are calculated. 


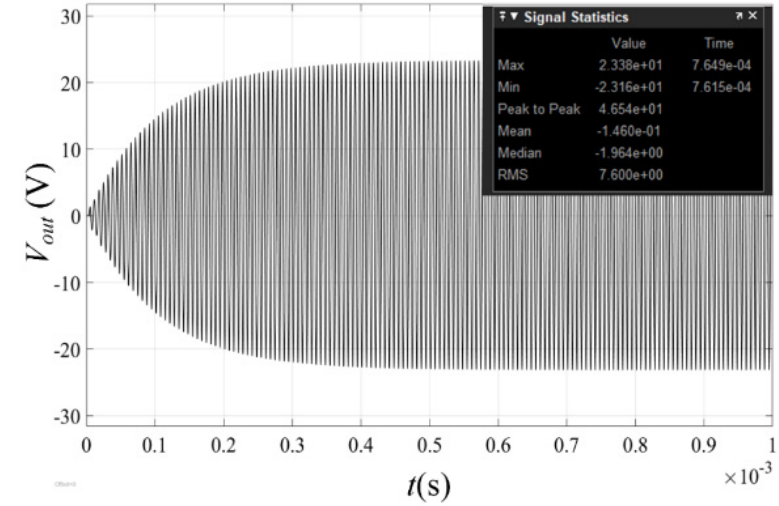

(a)

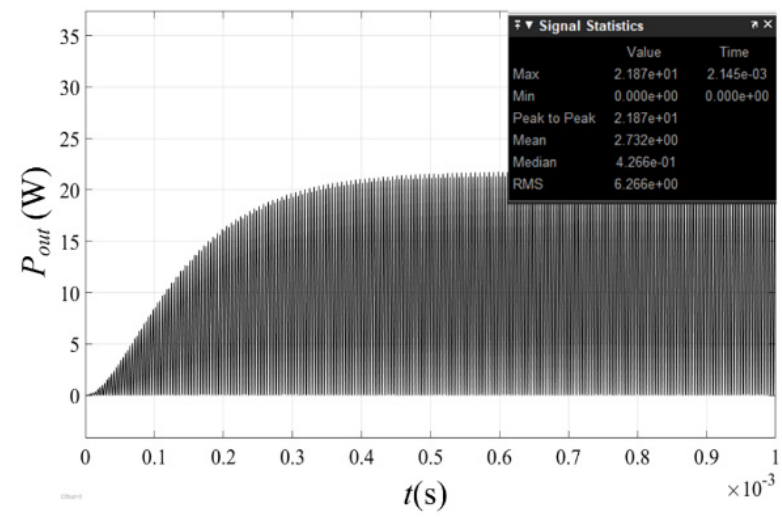

(b)

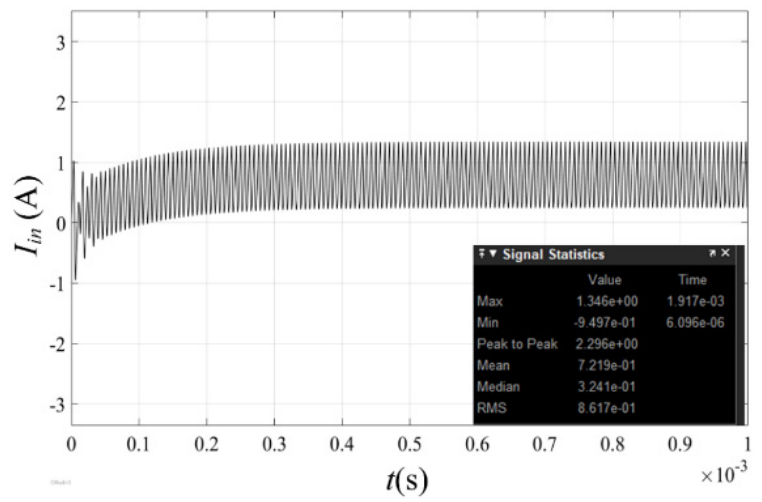

(c)

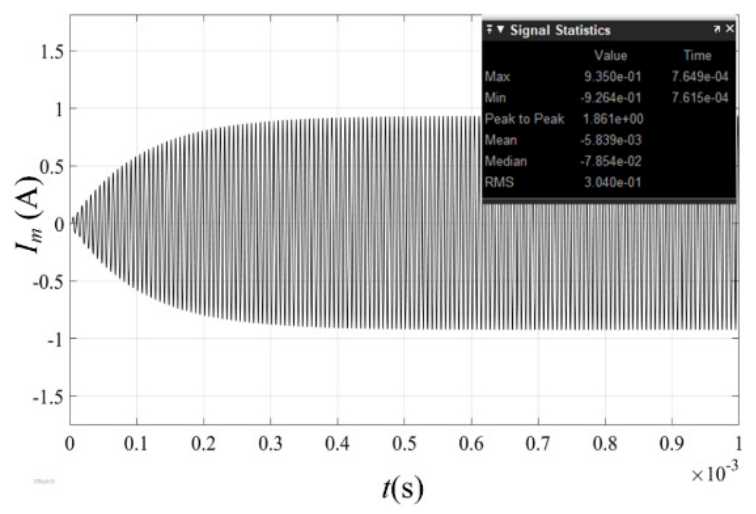

(d)

Figure 13. The (a) $V_{\text {out }}$ at $D=0.50(\mathbf{b}) P_{\text {out }}$ at $D=0.50(\mathbf{c}) I_{\text {in }}$ at $D=0.50\left(\mathrm{~d} I_{m}\right.$ at $D=0.50$.

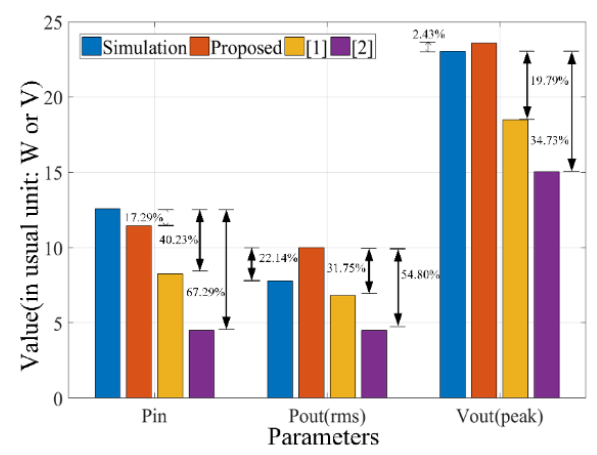

(a)

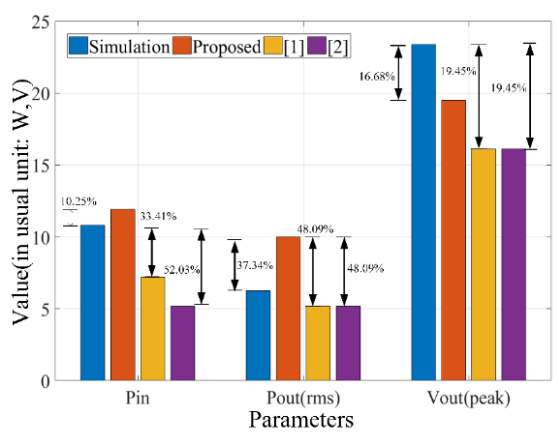

(c)

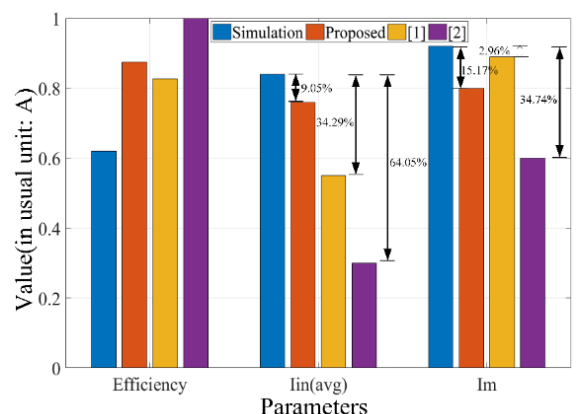

(b)

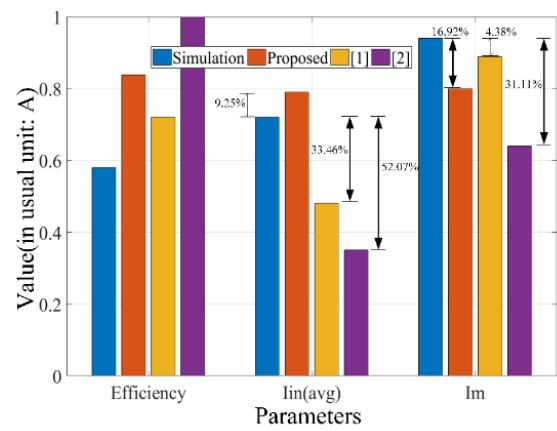

(d)

Figure 14. The comparison of the analytical and simulated results of (a) $P_{\text {in }}, V_{\text {out_peak }}$ and $P_{\text {out_rms }}$ at $D=0.55 ;(\mathbf{b}) \eta, I_{\text {in_avg }}$ and $I_{m}$ at $D=0.55 ;(\mathbf{c}) P_{\text {in }}, V_{\text {out_peak }}$ and $P_{\text {out_rms }}$ at $D=0.50 ;(\mathbf{d}) \eta, I_{\text {in_avg }}$ and $I_{m}$ at $D=0.50$. 
In Figure $14 \mathrm{a}$, at $D=0.55, V_{\text {out_peak }}$ and $P_{\text {in }}$ from the proposed model demonstrate a difference of $2.43 \%$ and $17.29 \%$ with the simulated value, respectively. For [1], these differences are maximum at $24.85 \%$ and $67.29 \%$, respectively. In Figure $14 \mathrm{~b}$, the proposed model demonstrates a difference of $9.05 \%$ and $15.17 \%$ for $I_{i n \_a v g}$ and $I_{m}$ while the maximum is $64.05 \%$ and $34.74 \%$, respectively, for [1].

In Figure $14 \mathrm{c}$, at $D=0.50, P_{\text {in }}, P_{\text {out_rms }}$ and $V_{\text {out_peak }}$ demonstrate a difference of 10.25 , 37.34 and $16.90 \%$, respectively, for the proposed model. These parameters demonstrate a maximum difference of 52.03, 48.09 and 19.45\%, respectively, for [1]. Again, in Figure 14d, a maximum difference of $52.07 \%$ in $I_{\text {in_avg }}$ and $31.11 \%$ in $I_{m}$ are observed for [1]. However, $I_{\text {in_avg }}$ and $I_{m}$ are most accurately determined by the proposed model and [2] demonstrating an error of $9.25 \%$ and $4.38 \%$, respectively.

In Figure 15, the input average current for the proposed model, the model in [1,2] and for the simulation is demonstrated against $D$. As obvious, the optimum operating condition for the proposed model is $D \approx 0.43$ to 0.61 . The shaded area stands for an error $\leq 10 \%$.

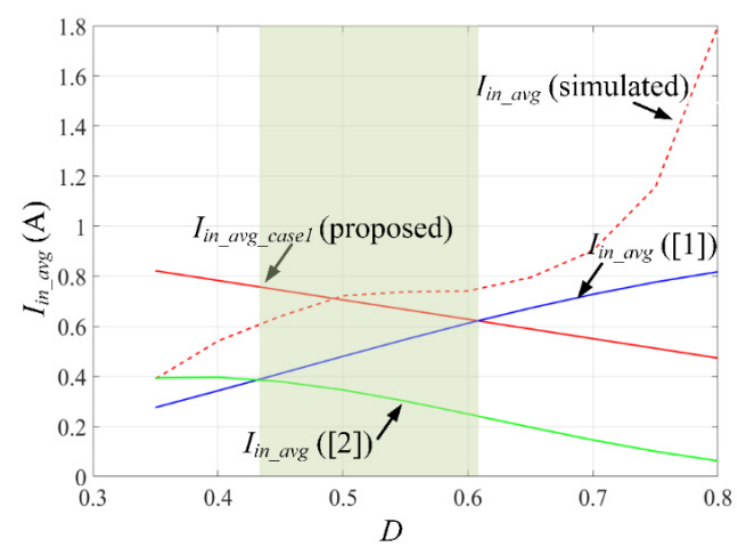

Figure 15. The input average current against $D$ (case 1) while $V_{\text {in }}=15 \mathrm{~V}, V_{\text {out_peak }}=20 \mathrm{~V}, P_{\text {out_rms }}=$ $10 \mathrm{~W}, D=0.50, f_{s}=150 \mathrm{kHz}$ and $L_{f}=50 \mu \mathrm{H}$.

As stated previously, this model is accurate when the input inductor is equal or close to the boundary value $\left(L_{f_{-} \text {boundary }}\right)$. Hence, the analytical value of $I_{\text {in }}$ should closely match to that from the simulation. In Figure 16, the input average current for the proposed model is compared with [1,2] and the simulation against $D$. The results are summarized in Table 2. As obvious, the percentage error between the analytical and simulated values are maximum when the input current is negative (at low $L_{f}$ ). As $L_{f}$ approaches to $L_{f \_b o u n d a r y}$, the current always remains positive. Subsequently, the error is minimized.

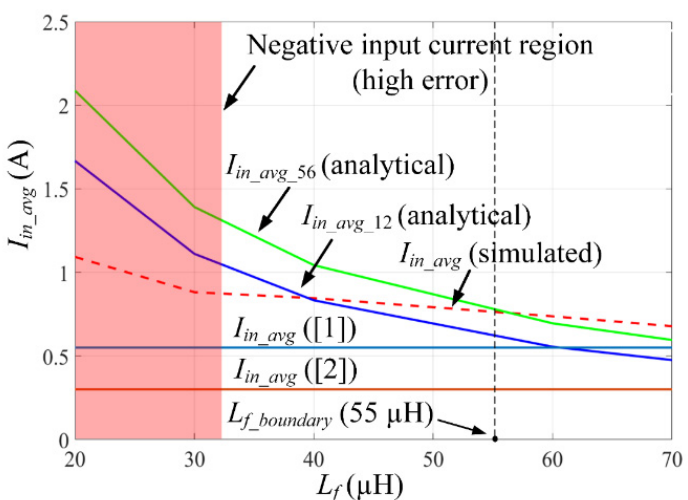

(a)

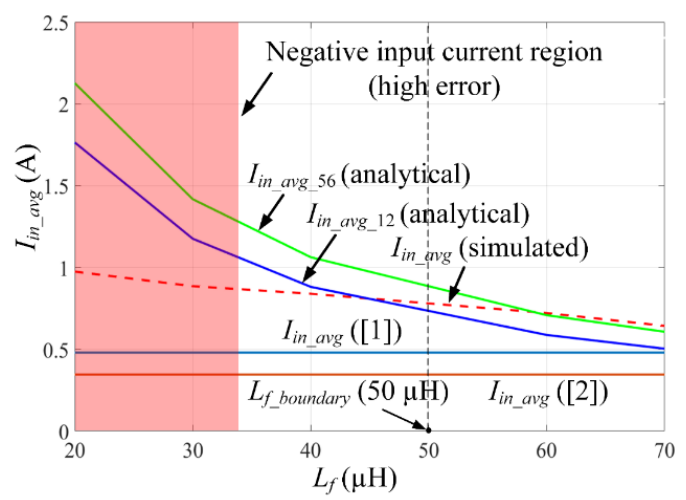

(b)

Figure 16. The average input currents vs $L_{f}$ : the analytical (proposed, [1,2]) and simulated values at $(\mathbf{a}) D=0.55$ and (b) $D=0.50$. 
Table 2. The input current comparison against $L_{f}\left(I_{\text {in_avg_12 }}\right.$ and $\left.I_{\text {in_avg_56 }}\right)$.

\begin{tabular}{|c|c|c|c|c|c|c|}
\hline \multicolumn{7}{|c|}{$D=0.55$} \\
\hline $\begin{array}{c}L_{f} \\
(\mu \mathrm{H})\end{array}$ & $\begin{array}{c}I_{\text {in_avg_12 }} \\
\text { (Analytical) } \\
(\mathrm{A})\end{array}$ & $\begin{array}{c}I_{\text {in_avg_56 }} \\
\text { (Analytical) } \\
(\mathrm{A})\end{array}$ & $\begin{array}{c}I_{\text {in_avg }} \\
\text { (Simulation) } \\
\text { (A) }\end{array}$ & $\begin{array}{c}\text { Error percentage } \\
\left(I_{\text {in_avg_12 }}\right. \\
\text { and simulation }) \\
(\%)\end{array}$ & $\begin{array}{c}\text { Error percentage } \\
\left(I_{\text {in_avg_56 }}\right. \\
\text { and simulation }) \\
(\%)\end{array}$ & $\begin{array}{c}\text { Ripple } \\
\text { (Simulation) } \\
(\%)\end{array}$ \\
\hline 20 & 1.6671 & 2.0871 & 1.0930 & 52.53 & 90.95 & 365.96 \\
\hline 30 & 1.1114 & 1.3914 & 0.8819 & 20.65 & 57.77 & 249.46 \\
\hline 40 & 0.8335 & 1.0435 & 0.8462 & 1.50 & 23.31 & 189.08 \\
\hline 60 & 0.5557 & 0.6957 & 0.7180 & 22.60 & 3.10 & 111.42 \\
\hline 70 & 0.4763 & 0.5963 & 0.6787 & 29.82 & 12.14 & 221.01 \\
\hline \multicolumn{7}{|c|}{$D=0.50$} \\
\hline $\begin{array}{c}L_{f} \\
(\mu \mathrm{H})\end{array}$ & $\begin{array}{c}I_{\text {in_avg_12 }} \\
\text { (Analytical) } \\
(\mathrm{A})\end{array}$ & $\begin{array}{c}I_{\text {in_avg_56 }} \\
\text { (Analytical) } \\
\text { (A) }\end{array}$ & $\begin{array}{c}I_{\text {in_avg }} \\
\text { (Simulation) } \\
\text { (A) }\end{array}$ & $\begin{array}{c}\text { Error percentage } \\
\left(I_{\text {in_avg_12 }}\right. \\
\text { and simulation }) \\
(\%)\end{array}$ & $\begin{array}{c}\text { Error percentage } \\
\left(I_{\text {in_avg_56 }}\right. \\
\text { and simulation }) \\
(\%)\end{array}$ & $\begin{array}{c}\text { Ripple } \\
\text { (Simulation) } \\
(\%)\end{array}$ \\
\hline 20 & 1.7639 & 2.1261 & 0.9751 & 80.89 & 118.03 & 358.93 \\
\hline 30 & 1.1759 & 1.4174 & 0.8859 & 32.73 & 59.99 & 237.04 \\
\hline 40 & 0.8819 & 1.0630 & 0.8398 & 5.01 & 26.57 & 178.61 \\
\hline 60 & 0.5880 & 0.7087 & 0.7219 & 18.54 & 1.82 & 145.44 \\
\hline 70 & 0.5040 & 0.6075 & 0.6435 & 21.67 & 5.59 & 108.78 \\
\hline
\end{tabular}

As $L_{f}$ continues to increase from $L_{f \_b o u n d a r y}, I_{\text {in_avg_56 }}$ provides better approximation

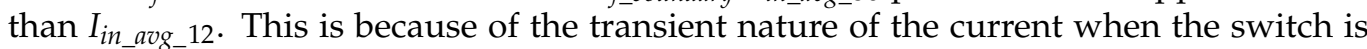
turned ON. The error is as low as $1.5 \%$ (for $I_{\text {in_avg_12 }}$ ) near $L_{f_{-} b o u n d a r y}$ and $3.10 \%$ (for $I_{\text {in_avg_56 }}$ ) at higher inductances. This is graphically shown in Figure $16 \mathrm{a}, \mathrm{b}$ where the high error region ( $>20 \%$ ) is shaded for $D=0.55$ and $D=0.50$, respectively. Accordingly, this region falls out of the scope of this model because of a significant error in approximating the average input current.

\subsection{Case-2: The Continuous Conduction Mode $(1<N<3)$}

As stated earlier, the input inductor is slightly greater than the $L_{f_{-} \text {boundary }}$ (approximately 1.5 to 2.5 times of $\left.L_{f_{-} \text {boundary }}\right)$. The analytical values of $V_{\text {out }}, P_{\text {out }}, I_{\text {in_avg }}$ and $I_{m}$ are derived in Section 3.2. In this section, the average input current for the proposed model as stated in (A15) is calculated and compared with the simulation results.

In Figure 17, the input average current for the proposed model, the model in [1,2] and for the simulation is demonstrated against $D$. The optimum operating condition for the proposed model is $D \approx 0.50$ to 0.63 . The shaded area stands for an error $\leq 10 \%$. 


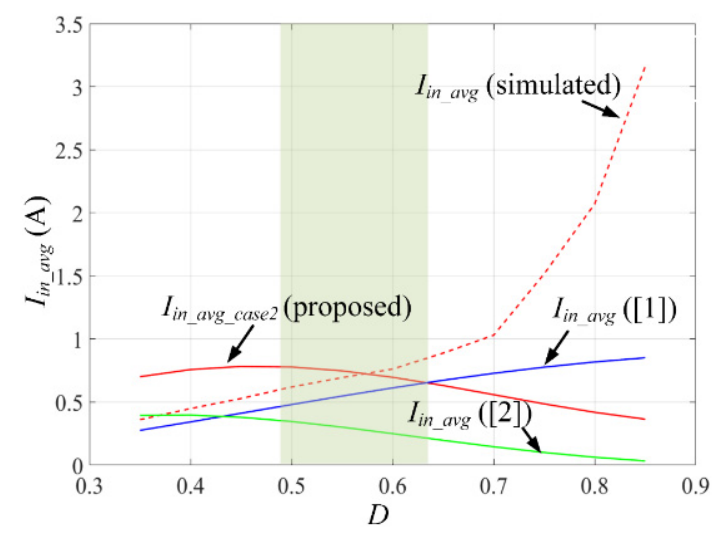

Figure 17. The input average current against $D$ (case 2) while $V_{\text {in }}=15 \mathrm{~V}, V_{\text {out_peak }}=20 \mathrm{~V}, P_{\text {out_rms }}=$ $10 \mathrm{~W}, \mathrm{D}=0.50, f_{s}=150 \mathrm{kHz}$ and $L_{f}=100 \mu \mathrm{H}$.

In Figure 18, the input average current for the proposed model is compared with [1,2] and the simulation against $D$. The analytical and simulation results are summarized in Table 3. Owing to the transient nature of the input current, $I_{\text {in_avg_56 }}$ gives rise to significant error in tracking the simulated values. The error becomes maximum, i.e., $44 \%$ and $36 \%$

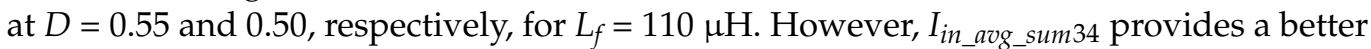
approximation of the input current as $L_{f}$ continues to increase. The minimum error of $0.36 \%$ and $16 \%$ is recorded at $D=0.55$ and 0.50 , respectively, for $L_{f}=110 \mu \mathrm{H}$. The results are graphically shown in Figure $18 \mathrm{a}, \mathrm{b}$ where the lower error region $(\leq 10 \%)$ is shaded.

Table 3. The input current comparison against $L_{f}\left(I_{\text {in_avg_56 }}\right.$ and $\left.I_{\text {in_avg_sum34 }}\right)$.

\begin{tabular}{|c|c|c|c|c|c|c|}
\hline \multicolumn{7}{|c|}{$D=0.55$} \\
\hline $\begin{array}{c}L_{f} \\
(\mu \mathrm{H})\end{array}$ & $\begin{array}{c}I_{\text {in_avg_56 }} \\
\text { (Analytical) } \\
\text { (A) }\end{array}$ & $\begin{array}{c}I_{\text {in_avg_sum } 34} \\
\text { (Analytical) } \\
\text { (A) }\end{array}$ & $\begin{array}{c}I_{\text {in_avg }} \\
\text { (Simulation) } \\
\text { (A) }\end{array}$ & $\begin{array}{c}\text { Error percentage } \\
\left(I_{\text {in_avg_56 }}\right. \\
\text { and simulation }) \\
(\%)\end{array}$ & $\begin{array}{c}\text { Error percentage } \\
\left(I_{\text {in_avg_sum } 34}\right. \\
\text { and simulation) } \\
(\%)\end{array}$ & $\begin{array}{c}\text { Ripple } \\
\text { (Simulation) } \\
(\%)\end{array}$ \\
\hline 80 & 0.5218 & 0.9385 & 0.6945 & 24.86 & 35.13 & 115.19 \\
\hline 90 & 0.4638 & 0.8343 & 0.6837 & 32.16 & 21.70 & 95.07 \\
\hline 100 & 0.4174 & 0.7508 & 0.6944 & 39.89 & 8.12 & 86.40 \\
\hline 110 & 0.3795 & 0.6826 & 0.6851 & 44.60 & 0.36 & 80.28 \\
\hline \multicolumn{7}{|c|}{$D=0.50$} \\
\hline $\begin{array}{c}L_{f} \\
(\mu \mathrm{H})\end{array}$ & $\begin{array}{c}I_{\text {in_avg_56 }} \\
\text { (Analytical) } \\
(\mathrm{A})\end{array}$ & $\begin{array}{c}I_{\text {in_avg_sum } 34} \\
\text { (Analytical) } \\
\text { (A) }\end{array}$ & $\begin{array}{c}I_{\text {in_avg }} \\
\text { (Simulation) } \\
\text { (A) }\end{array}$ & $\begin{array}{c}\text { Error percentage } \\
\left(I_{\text {in_avg_56 }} 56\right. \\
\text { and simulation) } \\
(\%)\end{array}$ & $\begin{array}{c}\text { Error percentage } \\
\left(I_{\text {in_avg_sum } 34}\right. \\
\text { and simulation }) \\
(\%)\end{array}$ & $\begin{array}{c}\text { Ripple } \\
\text { (Simulation) } \\
(\%)\end{array}$ \\
\hline 80 & 0.5315 & 0.9725 & 0.6200 & 14.27 & 56.85 & 129.17 \\
\hline 90 & 0.4725 & 0.8644 & 0.6193 & 23.70 & 39.57 & 129.03 \\
\hline 100 & 0.4252 & 0.7780 & 0.6198 & 31.39 & 25.52 & 80.67 \\
\hline 110 & 0.3868 & 0.7072 & 0.6096 & 36.54 & 16.01 & 78.74 \\
\hline
\end{tabular}




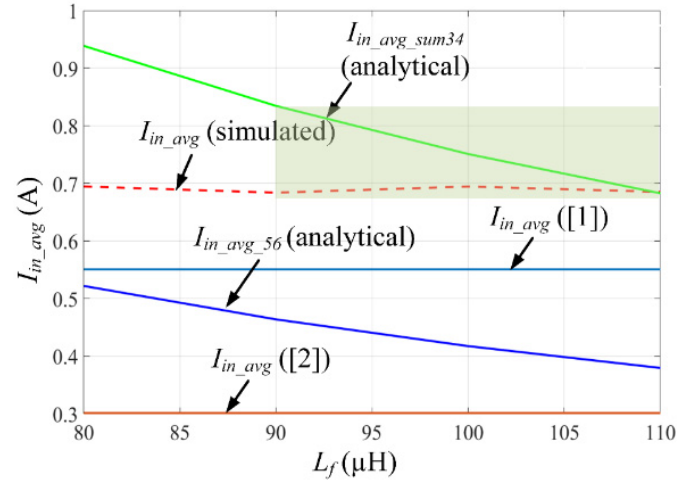

(a)

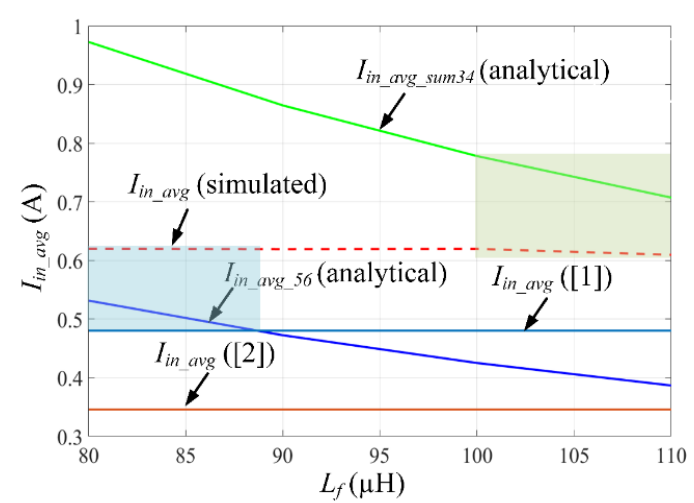

(b)

Figure 18. The average input currents vs $L_{f}$ : the analytical (proposed, [1,2]) and simulated values at (a) $D=0.55$ and (b) $D=0.50$.

\subsection{Case-3: The Continuous Conduction Mode $(N>3)$}

For case 3 , the input inductor is greater than the $L_{f_{-} \text {boundary }}$ (approximately 2.5 to 5 times of $L_{f \_ \text {boundary }}$ ). The analytical values of $V_{\text {out }}, P_{\text {out }}, I_{\text {in } \_ \text {avg }}$ and $I_{m}$ are derived in Section 3.2. In this section, the average input current for the proposed model as stated in (A19) is calculated and compared with the simulation results. In Figure 19, the input average current for the proposed model, the model in [1,2] and for the simulation is demonstrated against $D$. The optimum operating condition for the proposed model is $D \approx 0.50$ to 0.63 . The shaded area stands for an error $\leq 10 \%$.

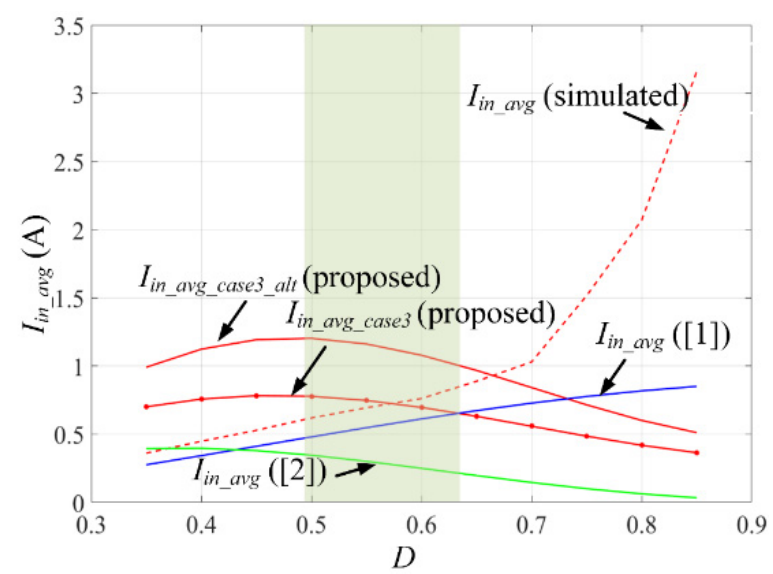

Figure 19. The input average current against $D$ (case 3$)$ while $V_{\text {in }}=15 \mathrm{~V}, V_{\text {out_peak }}=20 \mathrm{~V}, P_{\text {out_rms }}=$ $10 \mathrm{~W}, \mathrm{D}=0.50, f_{s}=150 \mathrm{kHz}$ and $L_{f}=200 \mu \mathrm{H}$.

In Figure 20, the input average current for the proposed model is compared with [1,2] and the simulation against $D$. The analytical and simulation results are summarized in Table 4. Owing to the transient nature of the input current, $I_{\text {in_avg_sum34 }}$ gives rise to significant error in tracking the simulated values at $L_{f}=160 \mu \mathrm{H}$. Beyond the latter, $I_{\text {in_avg_sum } 56}$ provides a better approximation of the input current than $[1,2]$ as $L_{f}$ continues to increase. The minimum error of $7.56 \%$ and $1.39 \%$ is recorded at $D=0.55, L_{f}=180$ and $D=0.50, L_{f}=200$, respectively. The results are graphically shown in Figure $20 \mathrm{a}, \mathrm{b}$ where the lower error region $(\leq 10 \%)$ is shaded. 


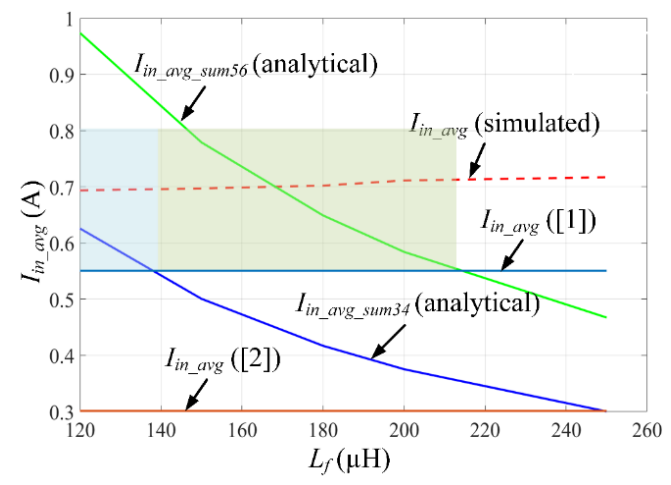

(a)

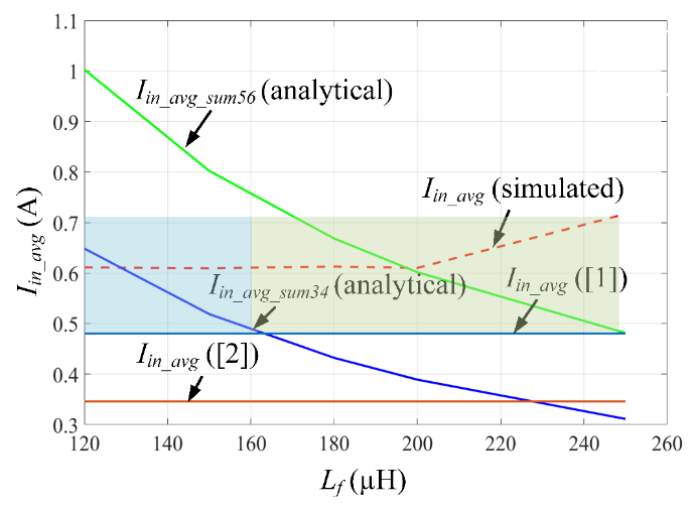

(b)

Figure 20. The average input currents vs $L_{f}$ : the analytical (proposed, [1,2]) and simulated values at (a) $D=0.55$ and (b) $D=0.50$.

Table 4. The Input Current Comparison ( $I_{\text {in_avg_sum34 }}$ and $\left.I_{\text {in_avg_sum56 }}\right)$.

\begin{tabular}{|c|c|c|c|c|c|c|}
\hline \multicolumn{7}{|c|}{$D=0.55$} \\
\hline $\begin{array}{c}L_{f} \\
(\mu \mathrm{H})\end{array}$ & $\begin{array}{c}\text { In_avg_sum34 } \\
\text { (Analytical) } \\
(\mathrm{A})\end{array}$ & $\begin{array}{c}\text { In_avg_sum56 } \\
\text { (Analytical) } \\
(\mathrm{A})\end{array}$ & $\begin{array}{c}I_{\text {in_avg }} \\
\text { (Simulation) } \\
(\mathrm{A})\end{array}$ & $\begin{array}{c}\text { Error percentage } \\
\left(I_{\text {in_avg_sum } 34}\right. \\
\text { and simulation) } \\
(\%)\end{array}$ & $\begin{array}{c}\text { Error percentage } \\
\left(I_{\text {in_avg_sum56 }}\right. \\
\text { and simulation) } \\
(\%)\end{array}$ & $\begin{array}{c}\text { Ripple } \\
\text { (Simulation) } \\
(\%)\end{array}$ \\
\hline 120 & 0.6257 & 0.9735 & 0.6936 & 9.78 & 40.35 & 72.08 \\
\hline 150 & 0.5006 & 0.7788 & 0.6970 & 28.17 & 11.73 & 60.25 \\
\hline 180 & 0.4171 & 0.6490 & 0.7021 & 40.59 & 7.56 & 54.12 \\
\hline 200 & 0.3754 & 0.5841 & 0.7112 & 47.21 & 17.87 & 35.15 \\
\hline 250 & 0.3003 & 0.4673 & 0.7169 & 58.11 & 34.81 & 27.89 \\
\hline \multicolumn{7}{|c|}{$D=0.50$} \\
\hline $\begin{array}{c}L_{f} \\
(\mu \mathrm{H})\end{array}$ & $\begin{array}{c}\text { In_avg_sum34 } \\
\text { (Analytical) } \\
(\mathrm{A})\end{array}$ & $\begin{array}{c}\text { In_avg_sum56 } \\
\text { (Analytical) } \\
(\mathrm{A})\end{array}$ & $\begin{array}{c}I_{\text {in_avg }} \\
\text { (Simulation) } \\
(\mathrm{A})\end{array}$ & $\begin{array}{c}\text { Error percentage } \\
\left(I_{\text {in_avg_sum } 34}\right. \\
\text { and simulation }) \\
(\%)\end{array}$ & $\begin{array}{c}\text { Error percentage } \\
\left(I_{\text {in_avg_sum56 }}\right. \\
\text { and simulation }) \\
(\%)\end{array}$ & $\begin{array}{c}\text { Ripple } \\
\text { (Simulation) } \\
(\%)\end{array}$ \\
\hline 120 & 0.6484 & 1.0027 & 0.6111 & 6.10 & 64.08 & 65.45 \\
\hline 150 & 0.5187 & 0.8021 & 0.6095 & 14.89 & 31.59 & 49.22 \\
\hline 180 & 0.4322 & 0.6684 & 0.6128 & 29.47 & 9.07 & 48.95 \\
\hline 200 & 0.3890 & 0.6016 & 0.6101 & 36.23 & 1.39 & 42.61 \\
\hline 250 & 0.3112 & 0.4813 & 0.7169 & 56.59 & 32.86 & 27.80 \\
\hline
\end{tabular}

The switch voltage and current waveforms are shown in Figure $21 \mathrm{a}, \mathrm{b}$ for $D=0.50$ and 0.55 , respectively, for case 1 . As expected, the switch voltage is either zero or negative at constant $d v_{s} / d t$. In Figure 21, the switch voltage and current waveforms are multiplied to measure the turn off losses. However, the exact switching loss would be nearly impossible to calculate from both a theoretical and simulation perspective. Instead, a very accurate relative estimate has been made from the simulated waveforms. As observed, the turn off loss ( $P_{\text {switching_loss_rms }}$ ) is approximately $0.72,1.2$ and $1.93 \%$ of the output power $\left(P_{\text {out_rms }}=7.786 \mathrm{~W}\right)$ for $D=0.50$ and 0.55 , respectively. In all cases, the turn on loss is negligible. The results are accumulated in Table 5 below. 


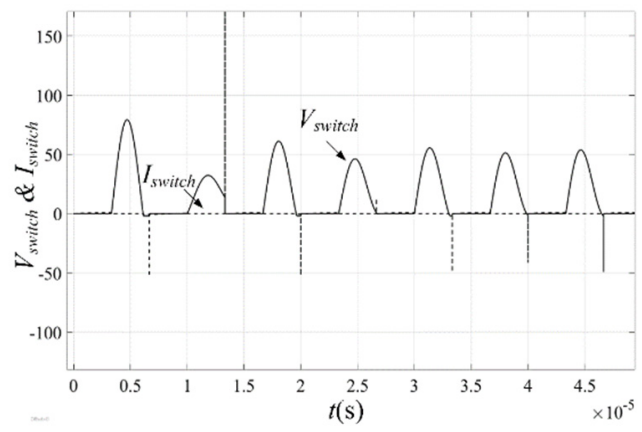

(a)

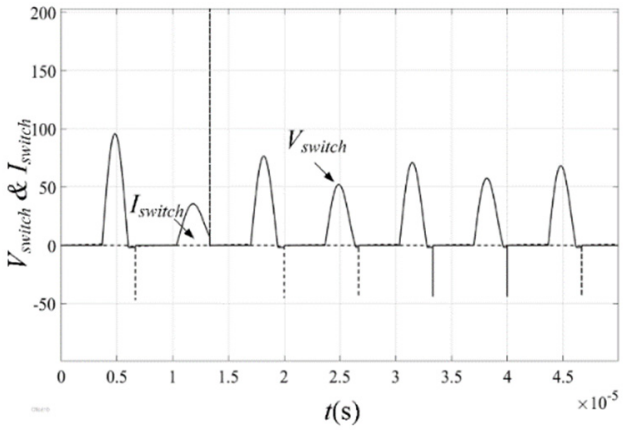

(b)

Figure 21. Case 1: (a) The switching waveforms at $D=0.50, L_{f}=50 \mu \mathrm{H}$ and $C_{i n}=12 \mathrm{nF}(\mathbf{b})$ The switching waveforms at $D=0.55, L_{f}=55 \mu \mathrm{H}$ and $C_{i n}=9 \mathrm{nF}$.

Table 5. The Approximate Switching Losses in Case 1, 2 and 3.

\begin{tabular}{cccccc}
\hline \multirow{2}{*}{ Case } & $\boldsymbol{D}$ & $\boldsymbol{L}_{f}(\boldsymbol{\mu H})$ & $\boldsymbol{C}_{\text {in }}(\mathbf{n F})$ & $\begin{array}{c}\boldsymbol{P}_{\text {switching_loss_rms }} \\
(\mathbf{m W})\end{array}$ & $\begin{array}{c}\text { Percentage Loss } \\
(\%)\end{array}$ \\
\hline \multirow{3}{*}{1} & 0.50 & 50 & 12 & 56.43 & 0.72 \\
\cline { 2 - 6 } & 0.55 & 55 & 9 & 93.95 & 1.20 \\
\cline { 2 - 6 } 2 & 0.60 & 70 & 5 & 150.8 & 1.93 \\
\hline \multirow{2}{*}{3} & 0.50 & 80 & 10 & 46.76 & 0.60 \\
\hline & 0.55 & 100 & 5 & 84.08 & 1.08 \\
\hline & 0.60 & 80 & 5 & 118.7 & 1.52 \\
\hline & 0.50 & 180 & 4 & 43.83 & 0.56 \\
\hline & 0.55 & 180 & 4 & 15.29 & 0.20 \\
\hline
\end{tabular}

The switch voltage and current waveforms are shown in Figure 22a,b for $D=0.50$ and 0.55 , respectively, for case 2 . As expected, the switch voltage is either zero or negative at constant $d v_{s} / d t$. In Figure 22, the switch voltage and current waveforms are multiplied to measure the turn off losses. As observed, the turn off loss $\left(P_{\text {switching_loss_rms }}\right)$ is approximately $0.60,1.08$ and $1.52 \%$ of the output power $\left(P_{\text {out_rms }}=7.786 \mathrm{~W}\right)$ for $D=0.50$ and 0.55 , respectively. In all cases, the turn on loss is negligible. The results are accumulated in Table 5.

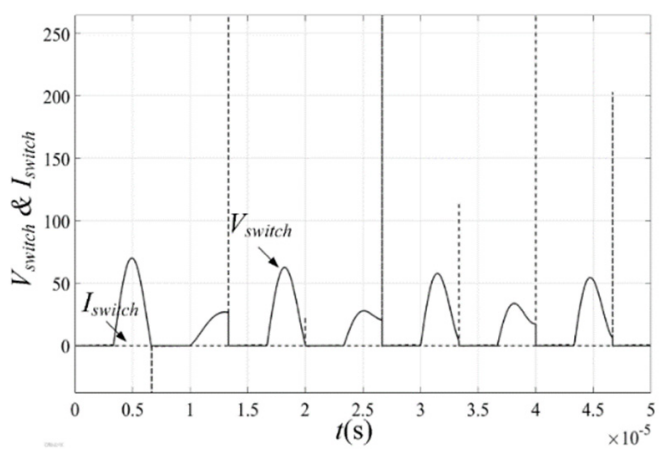

(a)

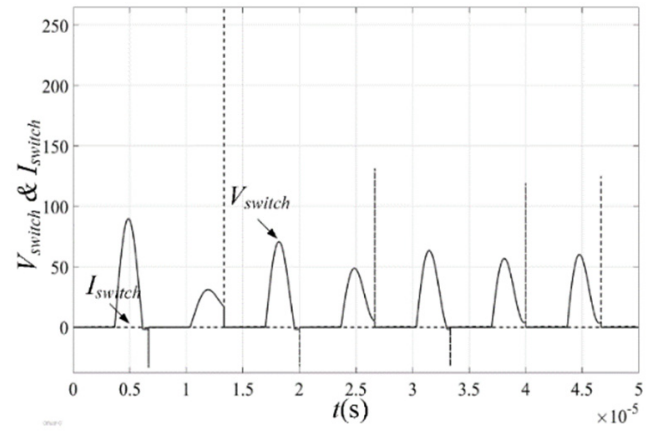

(b)

Figure 22. Case 2: (a) The switching waveforms at $D=0.50, L_{f}=80 \mu \mathrm{H}$ and $C_{i n}=10 \mathrm{nF}$ (b) The switching waveforms at $D=0.55, L_{f}=100 \mu \mathrm{H}$ and $C_{i n}=5 \mathrm{nF}$. 
The switch voltage and current waveforms are shown in Figure $23 \mathrm{a}, \mathrm{b}$ for $D=0.50$, 0.55 and 0.60 , respectively, for case 3. As expected, the switch voltage is either zero or negative at constant $d v_{s} / d t$. In Figure 23, the switch voltage and current waveforms are multiplied to measure the turn off losses. As observed, the turn off loss $\left(P_{\text {switching_loss_rms }}\right)$ is approximately $0.56,0.20$ and $1.27 \%$ of the output power $\left(P_{\text {out_rms }}=7.786 \mathrm{~W}\right)$ for $D=0.50$ and 0.55 , respectively. In all cases, the turn on loss is negligible. The results are accumulated in Table 5 below.

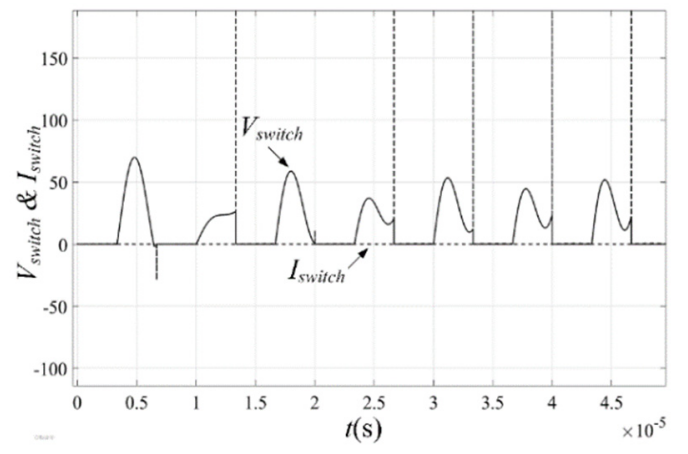

(a)

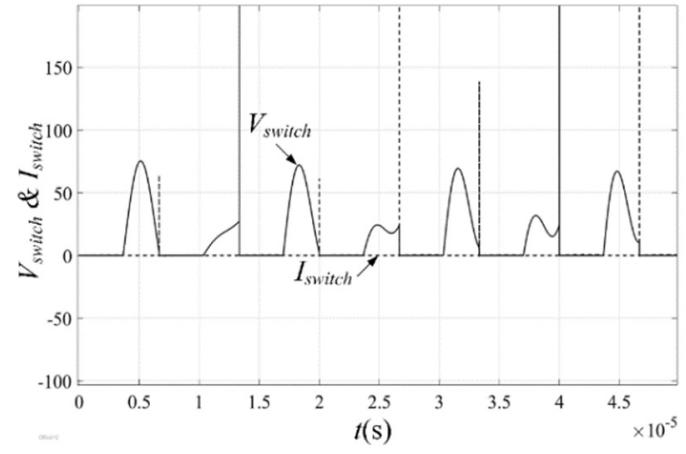

(b)

Figure 23. Case 3: (a) The switching waveforms at $D=0.50, L_{f}=180 \mu \mathrm{H}$ and $C_{i n}=4 \mathrm{nF}$ (b) The switching waveforms at $D=0.55, L_{f}=180 \mu \mathrm{H}$ and $C_{i n}=4 \mathrm{nF}$. and 3 .

In Figure 24, the switching waveforms reconfirms the ZVS achievement for case 1, 2

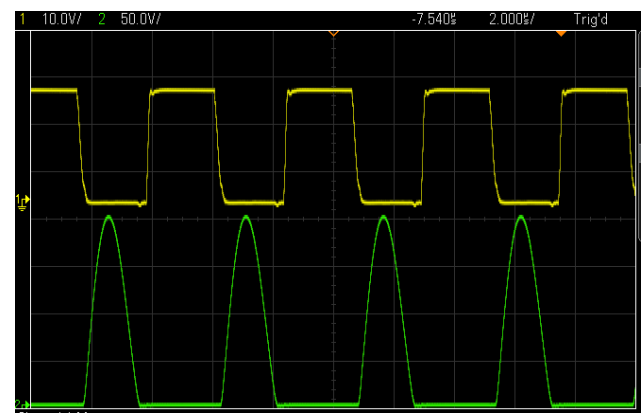

(a)

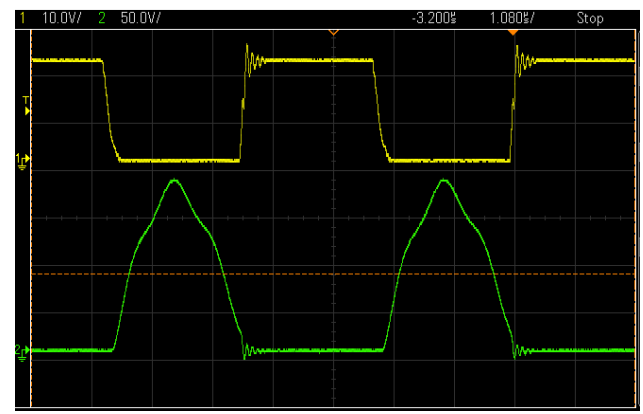

(b)

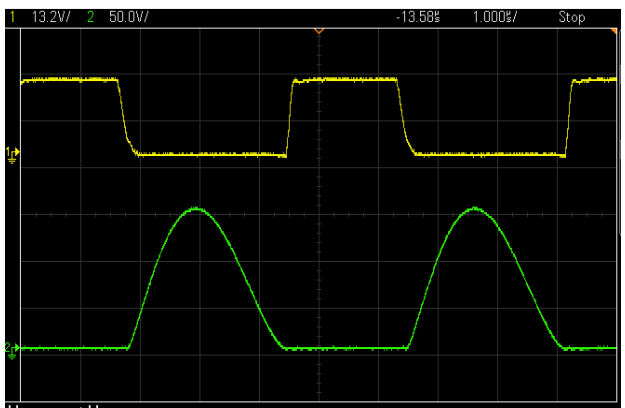

(c)

Figure 24. The switching waveforms at Case 1: (a) $D=0.50, L_{f}=50 \mu \mathrm{H}$ and $C_{\text {in }}=4 \mathrm{nF}$; Case 2: (b) $D=0.50, L_{f}=80 \mu \mathrm{H}$ and $C_{\text {in }}=10 \mathrm{nF}$; Case 3: (c) $D=0.50, L_{f}=180 \mu \mathrm{H}$ and $C_{\text {in }}=4 \mathrm{nF}$. 


\section{Conclusions}

In this paper, the class-E inverter is modeled and analyzed for ZVS/ZVDS implementation. The modeling is based upon determining the input current to the inverter for various input inductances and state of ripple current under a specified condition. A comprehensive simulation and experimental testing are performed to support the proposed analytical model. Eventually, as opposed to the existing models, the proposed model can determine the input current, input/output power, efficiency more accurately. The percentage of error is also determined for different size of the input inductor and the duty ratio. For most of the part, the percentage error increases with increasing input inductor size at higher duty ratio and decreases at lower duty ratio. This input current is also used to determine the input capacitance of the inverter to aid the ZVS/ZVDS execution. It is observed that the percentage loss is $<2 \%$ for all cases. In general, the results demonstrate that the proposed model is in better agreement with the test results as compared with the other existing models regardless of the input inductance and the input ripple current.

Author Contributions: Conceptualization, R.H.A.; data curation, M.H.M. and M.A.u.H.; formal analysis, A.S.M.S. (A. S. M. Shihavuddin), M.M.K. and J.A.; funding acquisition, A.I.; investigation, M.M.K. and M.S.B.A.; methodology, R.H.A. and J.A.; project administration, A.S.M.S. (A. S. M. Shihavuddin) and A.A.M.; resources, M.S.B.A. and A.S. (Ashraf Siddiquee); software, M.H.M.; validation, R.H.A.; visualization, R.H.A. and A.S. (Ashraf Siddiquee); writing-original draft, R.H.A.; writing-review and editing, A.A.M., M.A.u.H. and A.S. (Ashraf Siddiquee). All authors have read and agreed to the published version of the manuscript.

Funding: This research received no external funding. The APC was funded by Aminul Islam, from DTU, Lyngby, Denmark and ASM Shihavuddin from Green University of Bangladesh.

Conflicts of Interest: The authors declare no conflict of interest.

\section{Appendix A}

$$
\begin{aligned}
& v_{s}(\theta)=\frac{I_{m}(\cos (2 \pi D+\varphi)-\cos \varphi)(2 \pi D-\theta)-2 \pi I_{m}(\cos (2 \pi D+\varphi)-\cos (\theta+\varphi))(D-1)}{2 \pi \omega C_{i n}(D-1)} \\
& v_{S}(\theta)=\frac{\sqrt{\frac{2 P_{\text {out }, \text { rms }}}{R_{L}}}((2 \pi D-\theta)(\cos (2 \pi D+\varphi)-\cos \varphi)-2 \pi(D-1)(\cos (2 \pi D+\varphi)-\cos (\theta+\varphi)))}{2 \pi \omega C_{\text {in }}(D-1)} \\
& I_{\text {in__ } 1}(\theta)=f_{1}(\theta)+0 \\
& I_{\text {in } \_}(\theta)=f_{2}(\theta)+I_{\text {in } \_1}(2 \pi D)=f_{2}(\theta)+f_{1}(2 \pi D)+0 \\
& I_{\text {in_ } 3}(\theta)=f_{3}(\theta)+I_{\text {in_ } 2}(2 \pi)=f_{3}(\theta)+f_{2}(2 \pi)+f_{1}(2 \pi D)+0 \\
& I_{i n \_4}(\theta)=f_{4}(\theta)+I_{\text {in_3 } 3}(2 \pi(1+D))=f_{4}(\theta)+f_{3}(2 \pi(1+D))+f_{2}(2 \pi)+f_{1}(2 \pi D)+0 \\
& I_{\text {in_ } \_}(\theta)=f_{5}(\theta)+I_{\text {in_ }}(4 \pi)=f_{5}(\theta)+f_{4}(4 \pi)+f_{3}(2 \pi(1+D))+f_{2}(2 \pi)+f_{1}(2 \pi D)+0 \\
& f_{n}(\theta)=\frac{1}{\omega L_{f}} \int_{(n-1) \pi}^{\theta} V_{i n} d \theta \\
& f_{m}(\theta)=\frac{1}{\omega L_{f}} \int_{2 \pi\left(\frac{m-2}{2}+D\right)}^{\theta}\left(V_{\text {in }}-\left(\frac{1}{(D-1) \pi \omega C_{\text {in }}}\left(\left(\left(\pi-\frac{\theta}{2}\right) \cos (2 \pi D+\varphi)+\pi(D-1) \cos (\theta+\varphi)-\left(\pi D-\frac{\theta}{2}\right) \cos \varphi\right) \sqrt{\frac{P_{\text {out } r \text { rms }}}{R_{L}}}\right)\right)\right) d \theta \\
& I_{i n \_n}(\theta)=f_{n}(\theta)+f_{m}(\pi(n-1))+f_{n-2}\left(2 \pi\left(\frac{n-3}{2}+D\right)\right)+f_{m}(\pi(n-3))+\ldots \ldots \ldots . \\
& I_{\text {in_m } m}(\theta)=f_{m}(\theta)+f_{n}\left(2 \pi\left(\frac{(m-1)-1}{2}+D\right)\right)+f_{m-2}(\pi(m-2))+f_{n}\left(2 \pi\left(\frac{(m-3)-1}{2}+D\right)\right)+\ldots \ldots
\end{aligned}
$$




$$
\begin{gathered}
I_{\text {in_avg_case } 1}=\frac{1}{\omega^{2} L_{f} C_{\text {in }}}\left(\sqrt{\frac{2 P_{\text {out } r \text { rms }}}{R_{L}}}(1-D)\left(A \cos ^{2}(\pi D)+\sqrt{2} B \cos (\pi D) \sin (\pi D)+\sqrt{2} C+\pi(D-1) \cos \varphi\right)+4 V_{\text {in }} \pi \omega C_{\text {in }}\left(D^{2}-D+\frac{1}{2}\right)\right) \\
v_{S}(\theta)=\frac{1}{\omega C_{i n}} \int_{2 \pi\left(\frac{m}{2}-1+D\right)}^{m \pi}\left(\frac{\sqrt{\frac{2 P_{\text {out }, \text { rms }}}{R_{L}}}(\cos (2 \pi D+\varphi)-\cos \varphi)}{2 \pi(1-D)}-\sqrt{\frac{2 P_{\text {out }, r m s}}{R_{L}}} \sin (\theta+\varphi)\right) d \theta \\
I_{\text {in_avg_case1_alt }}=\frac{1}{2 \pi \omega L_{f}}\left(\int_{0}^{2 \pi(2+D)}\left(\int_{0}^{2 \pi(2+D)} V_{\text {in }} d \theta\right) d \theta+\int_{2 \pi(2+D)}^{6 \pi}\left(\int_{2 \pi(2+D)}^{6 \pi}\left(V_{\text {in }}-v_{S}(\theta)\right) d \theta\right) d \theta\right)
\end{gathered}
$$

$I_{\text {in_avg_case1_alt }}=\frac{1}{\omega^{2} L_{f} C_{\text {in }}}\left(\sqrt{\frac{8 P_{\text {out }, \text { rms }}}{R_{L}}}(D-1)\left(A^{\prime} \cos ^{2}(\pi D)-B^{\prime} \cos (\pi D) \sin (\pi D)-4 \pi \cos \varphi+\sin \varphi\right)+4 V_{\text {in }} \pi \omega C_{\text {in }}\left(D^{2}+D+\frac{5}{2}\right)\right)$

$$
P_{\text {out }, \text { rms }}=\left(-\frac{\sqrt{\frac{P_{\text {out }, \text { rms }}}{2 R_{L}}}(D-1)-\omega V_{\text {in }} C_{\text {in }}}{\omega^{2} L_{f} C_{\text {in }}}\right)^{2} \frac{2 R_{L}(\pi(1-D))^{2}}{(\cos (2 \pi D+\varphi)-\cos \varphi)^{2}}=\frac{V_{\text {out }, \text { peak }}}{2 R_{L}}
$$

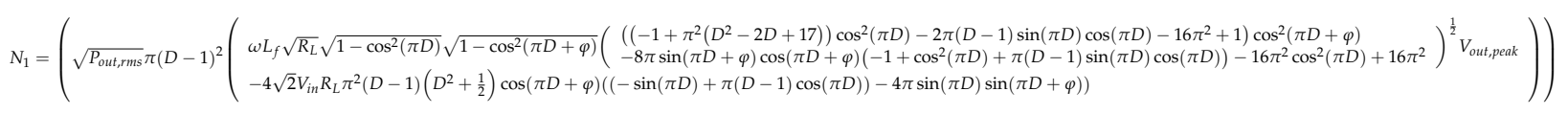

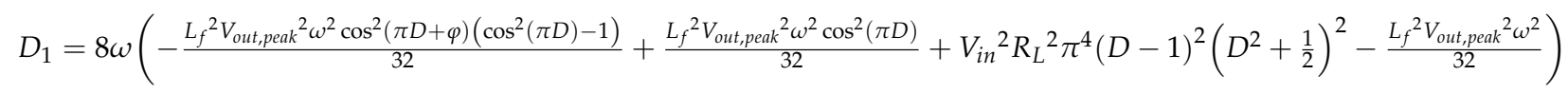

$$
I_{\text {in_avg_case } 2}=I_{\text {in_avg_78 }}=\frac{1}{2 \pi}\left(\int_{6 \pi}^{2 \pi(3+D)} I_{i n \_7}(\theta) d \theta+\int_{2 \pi(3+D)}^{8 \pi} I_{i n \_8}(\theta) d \theta\right)
$$

$I_{\text {in_avg_case } 2}=\frac{1}{\omega^{2} L_{f} C_{\text {in }}}\left(\sqrt{\frac{8 P_{\text {out } r \text { mms }}}{R_{L}}}(D-1)\left(A^{\prime} \cos ^{2}(\pi D)-B^{\prime} \cos (\pi D) \sin (\pi D)-4 \pi \cos \varphi+\sin \varphi\right)+4 V_{\text {in }} \pi \omega C_{\text {in }}\left(D^{2}+\frac{1}{2}\right)\right)$

$C_{\text {in_case } 2}=\frac{-\left(\pi(D-1)^{2}\left(\sin (\pi D+\varphi) \sin (\pi D)+\frac{1}{4}\right)\left(\sqrt{\frac{2 P_{\text {out }, \text { rms }}}{R_{L}}} \pi R_{L}{ }^{2} V_{\text {in }}(D-1)+\frac{\omega L_{f} V_{\text {out }, \text { peak }} \sin (\pi D+\varphi) \sin (\pi D)}{2}\right)\right)}{\left(\omega\left(-\frac{\omega^{2} L_{f}^{2} V_{\text {out }, \text { peak }}{ }^{2} \sin ^{2}(\pi D+\varphi) \sin ^{2}(\pi D)}{8}+\pi^{2} R_{L}{ }^{2} V_{\text {in }}{ }^{2}(D-1)^{2}\right)\right)}$

$I_{\text {in_avg_case3_alt }}=\frac{1}{\omega^{2} L_{f} C_{\text {in }}}\left(\sqrt{\frac{8 P_{\text {out } t \text { mms }}}{R_{L}}}(D-1)\left(A^{\prime \prime} \cos ^{2}(\pi D)-B^{\prime \prime} \cos (\pi D) \sin (\pi D)-14 \pi \cos \varphi+\sin \varphi\right)+4 V_{\text {in }} \pi \omega C_{i n}\left(D^{2}-D+\frac{1}{2}\right)\right)$

$$
\begin{aligned}
& v_{\mathcal{S}}(\theta)=\frac{1}{\omega C_{i n}} \int_{2 \pi\left(\frac{m}{2}-1+D\right)}^{m \pi}\left(\frac{\sqrt{\frac{2 P_{\text {out }, \text { rms }}}{R_{L}}}(\cos (2 \pi D+\varphi)-\cos \varphi)}{2 \pi(1-D)}-\sqrt{\frac{2 P_{\text {out }, r m s}}{R_{L}}} \sin (\theta+\varphi)\right) d \theta \\
& C_{\text {in_case3 }}=\frac{-\left(4 \pi(D-1)^{2}\left(\sin (\pi D+\varphi) \sin (\pi D)+\frac{3}{8}\right)\left(\sqrt{\frac{2 P_{\text {out }}, \text { rms }}{R_{L}}} \pi R_{L}^{2} V_{\text {in }}(D-1)+\frac{\omega L_{f} V_{\text {out }} \text { peak }}{\sin (\pi D+\varphi) \sin (\pi D) \sqrt{R_{L} P_{\text {out }, \text { rms }}}}\right)\right)}{\left(3 \omega\left(-\frac{\omega^{2} f_{f}{ }^{2} \text { out }_{\text {oenk }} \sin ^{2}(\pi D+\varphi) \sin ^{2}(\pi D)}{18}+\pi^{2} R_{L}^{2} V_{\text {in }}{ }^{2}(D-1)^{2}\right)\right)}
\end{aligned}
$$




\section{References}

1. Hayati, M.; Lotfi, A.; Kazimierczuk, M.K.; Sekiya, H. Analysis and Design of Class-E Power Amplifier With MOSFET Parasitic Linear and Nonlinear Capacitances at Any Duty Ratio. IEEE Trans. Power Electron. 2013, 28, 5222-5232. [CrossRef]

2. Ayachit, A.; Corti, F.; Reatti, A.; Kazimierczuk, M.K. Zero-Voltage Switching Operation of Transformer Class-E Inverter at Any Coupling Coefficient. IEEE Trans. Ind. Electron. 2019, 66, 1809-1819. [CrossRef]

3. Hayati, M.; Roshani, S.; Roshani, S.; Kazimierczuk, M.K.; Sekiya, H. Design of Class E Power Amplifier with New Structure and Flat Top Switch Voltage Waveform. IEEE Trans. Power Electron. 2018, 33, 2571-2579. [CrossRef]

4. Sheikhi, M.; Hayati, A.; Grebennikov, A. Design Methodology of Class-E/F3Power Amplifier Considering Linear External and Nonlinear Drain-Source Capacitance. IEEE Trans. Microw. Theory Tech. 2017, 65, 548-554. [CrossRef]

5. Hayati, M.; Sheikhi, A.; Grebennikov, A. Design and Analysis of Class E/ $F_{3}$ Power Amplifier with Nonlinear Shunt Capacitance at Nonoptimum Operation. IEEE Trans. Power Electron. 2015, 30, 727-734. [CrossRef]

6. Kessler, D.J.; Kazimierczuk, M.K. Power losses and efficiency of class-E power amplifier at any duty ratio. IEEE Trans. Circuits Syst. I Regul. Pap. 2004, 51, 1675-1689. [CrossRef]

7. Thongsongyod, C.; Ekkaravarodome, C.; Jirasereeamornkul, K.; Boonyaroonate, I.; Higuchi, K. High step-up ratio DC-DC converter using Class-E resonant inverter and Class-DE rectifier for low voltage DC sources. In Proceedings of the 2016 International Conference on Electronics, Information, and Communications (ICEIC), Danang, Vietnam, 27-30 January 2016; pp. $1-4$.

8. Niyomthai, S.; Sangswang, A.; Naetiladdanon, S.; Mujjalinvimut, E. Operation region of class E resonant inverter for ultrasonic transducer. In Proceedings of the 2017 14th International Conference on Electrical Engineering/Electronics, Computer, Telecommunications and Information Technology (ECTI-CON), Phuket, Thailand, 27-30 June 2017; pp. 435-438.

9. Rizo, L.; Ruiz, M.N.; García, J.A. Device characterization and modeling for the design of UHF Class-E inverters and synchronous rectifiers. In Proceedings of the 2014 IEEE 15th Workshop on Control and Modeling for Power Electronics (COMPEL), Santander, Spain, 22-25 June 2014; pp. 1-5.

10. Ma, K.; Chang, W.; Lee, Y. A simple CLASS-E inverter design for driving ultrasonic welding system. In Proceedings of the 2009 International Conference on Power Electronics and Drive Systems (PEDS), Taipei, Taiwan, 2-5 November 2009; pp. 894-896.

11. Ekbote, A.; Zinger, D.S. Comparison of Class E and Half Bridge Inverters for Use in Electronic Ballasts. In Proceedings of the Conference Record of the 2006 IEEE Industry Applications Conference Forty-First IAS Annual Meeting, Tampa, FL, USA, 8-12 October 2006; Volume 5, pp. 2198-2201.

12. Ashique, R.H.; Khan, M.M.; Shihavuddin, A.; Maruf, M.H.; Al Mansur, A.; ul Haq, M.A. A Novel Family of Class EF $n m$ and $\mathrm{E} / \mathrm{F}_{n m}$ Inverter for Improved Efficiency. In Proceedings of the 2020 2nd International Conference on Sustainable Technologies for Industry 4.0 (STI), Dhaka, Bangladesh, 19-20 December 2020; pp. 1-6.

13. Aldhaher, S.; Yates, D.C.; Mitcheson, P.D. Modeling and Analysis of Class EF and Class E/F Inverters with Series-Tuned Resonant Networks. IEEE Trans. Power Electron. 2016, 31, 3415-3430. [CrossRef]

14. Kaczmarczyk, Z.; Jurczak, W.A. Push-Pull Class-E Inverter with Improved Efficiency. IEEE Trans. Ind. Electron. 2008, 55, 1871-1874. [CrossRef]

15. Kazimierczuk, M.K.; Jozwik, J. DC/DC converter with class E zero-voltage-switching inverter and class E zero-current-switching rectifier. IEEE Trans. Circuits Syst. 1989, 36, 1485-1488. [CrossRef]

16. Li, Y.; Sue, S. Exactly analysis of ZVS behavior for class E inverter with resonant components varying. In Proceedings of the 2011 6th IEEE Conference on Industrial Electronics and Applications, Beijing, China, 21-23 June 2011; pp. 1245-1250. 